\title{
Winners and Losers of Early Elections: On the Welfare I mplications of Political Blockades and Early Elections
}

\author{
Felix Bierbrauer*
}

Lydia Mechtenberg**

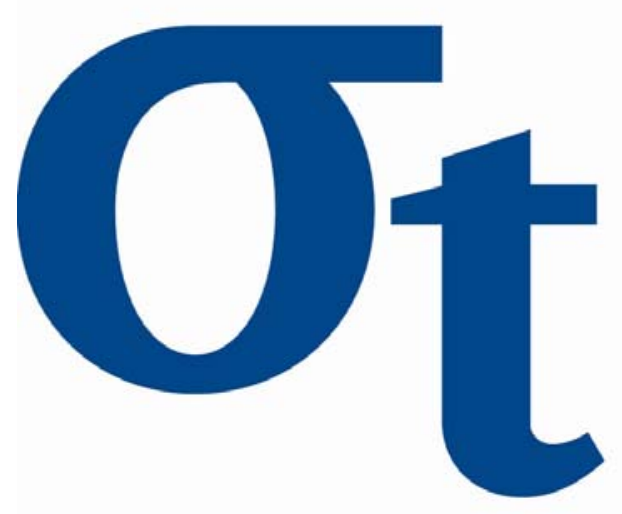

* MPI Bonn, Germany

** TU Berlin, Germany

This research was supported by the Deutsche Forschungsgemeinschaft through the SFB 649 "Economic Risk". 


\title{
Winners and Losers of Early Elections: On the Welfare Implications of Political Blockades and Early Elections* ${ }^{* \dagger}$
}

\author{
Felix Bierbrauer \\ MPI, Bonn \\ Lydia Mechtenberg \\ TU, Berlin
}

December 17, 2008

\begin{abstract}
We develop a dynamic model of political competition. Each party has a policymotivated ideological wing and an office-motivated opportunistic wing. A blockade arises if inner-party conflict stops policy implementation. We use this model to study whether early elections should be used to overcome a blockade. They have the advantage that urgent decisions are no longer delayed, and the disadvantage that unsuccessful governments gain additional time in office. This may give rise to a time inconsistency. Voters are in favour of a constitution without early elections. However, in the middle of a political crisis, they are willing to abandon it.
\end{abstract}

Keywords: early elections, political blockades, ideological rigidities

JEL: D72, D61, D82

\footnotetext{
${ }^{*}$ We benefited from comments by Christoph Engel, Martin Hellwig, Michael Kurschilgen, Stephan Tontrup, Philipp Weinschenk, and Max Wolf. We are grateful to Seminar participants at the Humboldt University, Berlin, and the Free University, Berlin, and to Carina Woodage for excellent research assistance.

${ }^{\dagger}$ This research was supported by the Deutsche Forschungsgemeinschaft through the SFB 649 "Economic Risk".
} 


\section{Introduction}

Throughout a large part of the democratic world, the timing of general elections is flexible; that is, the government has the constitutional right to call an early election. However, the use that is made of this right is typically controversial. For instance, Margaret Thatcher was accused of "cutting and running" when she called an election in 1983, shortly before the inflation rate went up, and thereby capitalized on high polls in the nick of time. Generally, a snap election is met with criticism whenever the feeling prevails that the reasons behind it are purely tactical.

Faced with this critique, politicians try to justify their calling of early elections. One possible route is to argue that unexpected political developments imply that the government needs a timely new mandate from the electorate. Alternatively, early elections are often argued to be a means of ending a political crisis. Both arguments were used in Germany in 2005, when chancellor Gerhard Schröder called an early election. He argued that "without a new mandate my political programme cannot be carried forward" (The Independent, 2 July 2005). The German president, whose consent was needed for an early election to take place, emphasized the country's exigent need of a strong government capable of enforcing needful though controversial reforms. Similarly, Japan's prime minister in 2005, Junichiro Koizumi, justified calling an early election with the purpose to pursue a controversial reform (the privatization of the national post) against the opposition in the parliament.

This shows that there are acceptable reasons for an early election, such as the need for a new mandate or the need to overcome a political crisis, and illegitimate, or purely tactical reasons, such as the incumbent government's chance of winning an early election. The question that is naturally implied by this distinction is: Are voters who are facing an upcoming snap election able to discern whether the motives behind it are legitimate or not?

To see the bearing of this question, suppose for the moment that the answer was Yes. Then, voters would be in the position to punish politicians with illegitimate motives for an early election. They would simply refrain from reelecting them. Thus, any wise government would in turn refrain from initiating a snap election for the wrong reason; and the problem, if there was any, would be solved by self-regulation of the democratic system.

The situation is different if voters are not able to discern the motives behind an upcoming snap election. An agency problem arises because politicians remain undetected if they appeal to legitimate reasons in order to justify an illegitimate early election. In this case, constitutional law must either allow early elections in general or ban them in general. This raises the question about the criteria according to which such a constitutional decision has to be made. How should the possibility of both legitimate and illegitimate early elections affect the assessment of early elections at the constitutional level?

To address these questions, this paper develops a model in which both legitimate 
and illegitimate reasons for early elections are clearly defined, and in which a welfare analysis of different constitutional rules can be carried out.

\section{A sketch of the model}

The following three properties of our model drive the analysis. First, a government may be competent or incompetent in the sense that it is able to identify what policy is in the voters' interest. Second, there is a ruling party, whose support is important for the government, and which consists of an office-motivated "opportunistic" wing and a policy-motivated "ideological" wing. ${ }^{1}$ Third, the ruling party's majority in parliament may either be large or small. ${ }^{2}$ In the latter case, the influence of the ideological wing is assumed to be larger because it is essential for the government's majority in parliament. ${ }^{3}$

To illustrate the interplay of these assumptions, suppose that the reduction of unemployment rates is the most urgent political problem and that there are two types of policy measures that can be used. On the one hand, Keynesian policies which stimulate macroeconomic activity and are favored by the ideologues in the left party. One the other hand, there are policies which improve individual incentives to seek for employment, e.g., via a reduction of unemployment benefits, and which are favored by the ideologues in the right party. Suppose that, depending on current economic conditions, only one of these policy measures effectively reduces unemployment. We say that a government is competent if it understands what the effective policy measure is, and is incompetent otherwise.

In this setting, the incentives of a prime minister to call an early election depend both on the expected success in the reduction of unemployment, and on whether the current majority in parliament is large or small. To see this, consider the interaction of a rational voter (he) with an office motivated prime minister (she).

The prime minister will call an early election only if she believes that her current reelection chances are greater than they will be at the next regular election. What voters can therefore infer from the fact that an early election takes place is that unemployment will not go down prior to the next regular election. In principle, this may have two reasons: Either the prime minister is not capable of reducing unemployment, i.e., she is incompetent, or, parliament prevents the implementation of effective policies.

If the ruling party has a large majority in parliament, then there is no need to compromise with the ideologues so that the persistence of unemployment can be attributed only to the prime minister's incompetence. By contrast, if the ruling party's

\footnotetext{
${ }^{1}$ In Section 5 we study an extended model which makes it possible to provide a rigorous foundation of this assumption. In particular we show that it may be optimal for a party to have an ideological and an opportunistic wing, even if the sole objective of all party members is to be ruling as often as possible.

${ }^{2}$ In our model, this is an equilibrium outcome that is implied by the rational behavior of voters.

${ }^{3}$ Empirically, there are of course several possible reasons why government stability may be endangered by a small majority. Our model focusses on only one of them, which is inner-party conflict. For instance, Germany's early election in 2005 became necessary because the left wing of the ruling social-democratic party no longer supported the government's labour market reforms.
} 
majority is small, it may also be due the fact that the policy that effectively reduces unemployment is unacceptable to the ruling party's ideologues.

In the latter situation, the prime minister's incentives to call an early election depend on the voters' beliefs, i.e., on the probability that they assign to the possibility that she would be able to reduce unemployment if only her majority in parliament was larger. Put differently, she can use an early election to gain additional time in office only if the voters are confident that she is competent.

Given such beliefs, however, early elections are attractive for any prime minister, competent or not, who knows that unemployment will not go down before the next regular election. Moreover, early elections are more often attractive for an incompetent prime minister than for a competent one, because the latter can occasionally reduce unemployment, namely whenever the effective policy is compatible with the ruling party's ideologues. The voter must therefore rationally believe that a prime minister who calls an early election is much more likely to be incompetent than competent. Consequently, only if the opposition's candidate makes an even worse impression will the voter reelect the prime minister at an early election.

There are two conclusions from these considerations. First, the voter cannot discern whether the motives behind a given snap election are legitimate or not. The reason is that an incompetent prime minister can always blame the need to compromise with the ideologues for her lack of success. Second, an early election confronts the voter with the choice between a prime minister who is unlikely to be competent and an alternative candidate who is even worse. This follows because the incumbent prime minister calls an early election only if she is sufficiently likely to win. But this requires that the opposition candidate must appear even less appealing to the voters. ${ }^{4}$ These two insights seem plainly to imply that a constitutional ban on early elections would be optimal from the perspective of the voter.

However, this downside is potentially counterbalanced by the fact that early elections affect the timing of political decisions. We assume that the major political initiatives of a government are undertaken shortly after an election. This assumption is meant to capture a stylized fact. In parliamentary democracies, political activity declines as the end of the legislative period approaches for a variety of reasons. Politicians start to prepare themselves for the upcoming election, the current leaders potentially suffer from a lame-duck effect, or the current government seeks to avoid controversies as the next election comes closer.

Consequently, an early election implies that the next substantial political decision is taken earlier. In our example, given that unemployment will not go down prior to the next regular election, an early election offers the chance that the effective policy against unemployment can be implemented immediately, rather than after the next regular election.

These considerations show that the answer to the question whether a political consti-

\footnotetext{
${ }^{4} \mathrm{~A}$ possible reason is that the opposition party is surprised enough by the timing of the election to be unable to produce a suitable candidate. See Smith (2004) for empirical evidence on this.
} 
tution should include the possibility to call an early election depends on the assessment of a quality-urgency-tradeoff. One the one hand, it is more likely that an early election prolongs the career of an incompetent prime minister. This gives rise to a negative quality effect. On the other hand, urgent political decisions can be realized sooner, if early elections are possible.

At this point, however, a new problem arises. A constitutional ban on early elections might be unstable due to a time inconsistency. While it might be preferable from an ex ante perspective to ban early elections by constitutional law, since the expected urgency of political decisions might be low, a situation might arise where a political decision has actually become very urgent. In such a situation, both the voter and the prime minister may want to change the constitution and have a snap election; the voter because of the urgency of the political decision and the prime minister to prolong her time in office. Once changed, however, the constitution will remain stable. Politicians benefit from the possibility of early elections and will hence not support a further constitutional change. Hence, a stable constitution that precludes early election may be difficult to achieve.

\section{Related Literature}

There are two broad categories of literature, to which our paper contributes. The first category, obviously, is the literature on election timing. The second one, is the political economy literature in general, to which we add a new model of political competition. The existing literature on election timing has three branches. First, Lupia and Strom (1995) and Diermeier and Merlo (2000) model early elections as an exogenous outside option in parliamentary bargaining, i.e., early elections occur when there is no bargaining solution. In these models, the reactions of voters to parliamentary crises are not explicitly modelled.

Second, opportunistic election timing by politicians is analyzed by the literature on "surfing" and "manipulation". The literature on "surfing" models the timing of elections as a strategic reaction to exogenous movements of the polls. For instance, Keppo et al. (2007) assume that the timing of elections is analogous to the decision about the optimal exercise time of an American option. They derive an optimal stopping rule for the incumbent party. ${ }^{5}$ The literature on "manipulation", by contrast, assumes that the ruling party can strategically influence its popularity. ${ }^{6}$ These papers, too, do not explicitly model the behavior of voters.

The third branch of the literature on election timing is the seminal work of Alastair Smith (Smith (1996, 2004)). Smith provides a signalling model of election timing in which both politicians and voters are explicitly modelled. However, Smith abstracts

\footnotetext{
${ }^{5}$ For an early contribution that models election timing as an optimal stopping problem, see Balke (1990).

${ }^{6}$ Such models are provided by some papers within the literature on political business or budget cycles that consider flexible election terms, e.g., by Chapell and Peel (1979), Lächler (1982), and most notably Kayser (2005).
} 
from the role of early elections as a solution to a political blockade or parliamentary crisis.

Our model links these literatures in that it has parliamentary conflicts, opportunistic election timing, signalling and rational, forward-looking voters. Moreover, our focus on the legitimacy of early elections distinguishes the current paper from the existing literature. In particular, we provide a careful analysis of the welfare implications of early elections.

The methodological contribution of our paper is the development of a dynamic model of political competition that makes it possible to explain the existence of different party wings and the emergence of ideological rigidities. ${ }^{7}$ With repeated interactions and heterogeneous voters, we can show that an office-motivated party may at the same time have a long standing loyalty to voters with extreme policy preferences and try to gain the support of the median voter. For instance, a left party will occasionally block policies that are very unattractive to the very leftist voters. It has an interest to do so because otherwise the very leftist voters would abstain in future elections and the position of the left party relative to the right party would be weakened. In other circumstances, it will implement the median voter's preferred policy. Again this follows from the repeated interaction of the voters and the party. If the left party won an election because of the median voter's support and then implemented extreme partisan policies, then the voters surrounding the median position would refuse to vote for the left party in the future.

The remainder is organized as follows. In Section 2, we introduce a simple model of political blockades. Section 3 introduces early elections to this setup. The welfare effects of early elections are discussed in Section 4. In Section 5, we study an extended model with heterogeneous voters and uncertainty about the outcome of early elections. This makes it possible to endogenize the existence of ideological party wings. The last section contains concluding remarks. All proofs are in the Appendix.

\section{A model of political blockades}

In the following, we develop a simple model of political blockades. We assume initially that early elections are not possible. They will be introduced in the following section. A main feature is that a blockade is possible whenever the government is supported only by a small majority of the members of parliament. As will become clear, the consequence of a blockade is that a competent prime minister will not be reelected because she is unable to prove her competence to the voters.

We first describe the actors in the political process; in particular what actions they take and what preferences they have. We will then specify the sequence of events. Once

\footnotetext{
${ }^{7}$ An appeal to repeated interaction and ideological policy motives can also be found in Roemer (1999), even though the latter is a static model of political competition. Moreover, Roemer (1999) assumes rather than explains that there are different party wings.
} 
these preliminary steps are taken, we can turn to the equilibrium analysis.

\subsection{The actors in the political process}

\section{Voters}

Voter utility in period $T$ is given by

$$
u_{T}=g_{T}-\left(\frac{1}{2}+\omega_{T}-p_{T}\right)^{2} .
$$

$g_{T}$ is the per capita utility from a political decision taken at date $T{ }^{8}$ This utility is reduced according to a quadratic loss function if the chosen policy, $p_{T}$, does not coincide with the ideal policy from the perspective of voters. $\omega_{T}$ is the state of the economy in period $T$. It takes values in the unit interval and affects the preferred policy of voters, $p_{T}^{*}=\frac{1}{2}+\omega_{T}$.

The following terminology will prove useful. If $\omega_{T} \geq \frac{1}{2}$ or, equivalently, $p_{T}^{*} \geq 1$, then we say that the voters' preferred policy is rightist, and leftist otherwise. Voters wish that the chosen policy matches the state of the world. This implies, in particular, that they prefer leftist policies over rightist policies if $\omega_{T} \geq \frac{1}{2}$ and prefer rightist policies over leftist policies otherwise.

\section{The prime minister}

Policy is chosen by the prime minister. We assume that, once in office, the prime minister learns whether or not she is of the competent type $(t=c)$ or of the incompetent type $(t=i)$. A competent prime minister learns $\omega_{T}$ before making her policy proposal. An incompetent prime minister does not observe the current value of $\omega_{T}$.

$\omega_{T}$ is taken to be the realization of a random variable that is uniformly distributed on the unit interval. This implies that an incompetent prime minister is unable to guess the true state of the economy; i.e., if she picks some policy at random, it is equal to $p_{T}^{*}=\frac{1}{2}+\omega_{T}$ with probability 0 .

To motivate these assumptions, suppose that competence is the ability to implement policy measures that effectively reduce unemployment. Once she has become head of the government, the prime minister gets a more precise idea about the support and the opposition that alternative policy measures will face because she is addressed by special interest groups and interacts with the experts from the ministries that are responsible for the details of policy implementation. We think of competence as an ability to deal with this situation and finally to come up with a policy that indeed helps to reduce unemployment. Moreover, we assume that whether or not a prime minister possesses this competence cannot be determined before she is in office.

\footnotetext{
${ }^{8}$ As will become clear, assumptions about $g_{T}$ will be important for the welfare analysis of electiontiming decisions. For instance, if we set $g_{T}$ equal to zero, then every political decision would be a public bad, creating only losses for voters. This extreme assumption would imply that a good political constitution deters political decision-making. In Section 5, where we discuss the welfare implications of early elections, we also discuss which assumptions on $g_{T}$ are plausible in our model.
} 
Formally, we treat competence as private information of the prime minister. The consequences of her actions will possibly reveal information about her type to the voters. However, this information is not available when a candidate for prime minister is running for the first time. For simplicity, we assume that the prior probability that a newcomer is competent equals $k_{0}=\frac{1}{2}$.

A prime minster's time in office is limited. She can be in office for at most two legislative periods. ${ }^{9}$ We assume that the prime minister is primarily office-motivated. Only if she is indifferent with respect to two alternatives that are equivalent in terms of their implications for office holding, we assume that she prefers the one that is preferred by the voters.

As will become clear from the equilibrium analysis, these assumptions imply that a prime minister of the competent type wants voters to understand that she is competent in order to be reelected. However, whether this information is revealed to voters depends on the situation in parliament.

\section{Parliamentary Blockades}

The prime minister's policy proposals need to be accepted in parliament. We assume that there is a ruling party and an opposition party. The prime minister is a member of the ruling party. The opposition party's members of parliament never support political initiatives of the prime minister. As a consequence, the prime minister's policy proposals are accepted in parliament if and only if the prime minister's party approves the prime minister's policy choice.

We assume that there is a leftist party, $L$, and a rightist party, $R$. However, these parties are not homogeneous. Each party has an "opportunistic" party wing which cares about office holding and an "ideological" party wing whose members have a specific policy preference. We do not equip the ideologues with an own payoff function that distinguishes them from the opportunists, but just describe their behavior. ${ }^{10}$ In particular, the ideologues from party $L$ do not accept rightist policies, defined by $p_{T}>1$, and the ideologues from party $R$ do not accept leftist policies.

The relative importance of the two party wings depends on the size of the majority that the ruling party has in parliament. We define a large majority as any situation where the vote share of the ruling party exceeds a threshold level $s>\frac{1}{2}$. A small majority is a situation where the vote share of the ruling party lies between $s$ and $\frac{1}{2}$.

The size of the majority affects the prime minister's flexibility. If the ruling party has a large majority, then the prime minister can implement any policy she likes. However, if the majority is small, then her policy choice is restricted. A prime minister who belongs to party $L(R)$ and has a small majority in parliament chooses policy subject

\footnotetext{
${ }^{9}$ The important assumption for the logic of the model is that the prime minister's time horizon is finite. This implies that an incumbency advantage does not last forever.

${ }^{10}$ In Section 5 we study an extended model which makes it possible provide a foundation of this behavior. In particular, we show that it is consistent with opportunists and ideologues having the same preference for being in office.
} 
to the constraint that $p_{T} \leq 1\left(p_{T} \geq 1\right)$, i.e., subject to the constraint that members from the ideological party wing accept the policy proposal. More formally, a political blockade is defined as follows: the ruling party has only a small majority in parliament and the voters' preferred policy is not in the prime minister's choice set.

There are two possible interpretations of our model of political blockades. On the one hand, we can think of it literally as referring to a majoritarian system with only two parties, where each party has an opportunistic and an ideological wing. As argued by Roemer (1999), the existence and the persistence of such party wings is a stylized fact in political history. In this interpretation of the model, whether or not a majority is large or small affects the relative position of the two party wings for inner-party bargaining problems. We can think of a large majority as a situation such that the opportunistic party wing has an own majority in parliament which reduces the importance of reaching a consensus with the ideologues. ${ }^{11}$

On the other hand, we could interpret the opportunists and the ideologues on the left, say, as different parties that occasionally form a coalition government in a system with proportional representation. For instance, the opportunists on the left could be interpreted as a social democratic party that enters a coalition government with the socialists whenever they do not have an own majority in parliament. In this case, the constraint $p_{T} \leq 1$ captures that socialists and social democrats have to find a compromise if the left as a whole has only a small majority in parliament. ${ }^{12}$

\section{Political Parties}

In our model, political parties are important not only in parliament. They also select candidates for elections. ${ }^{13}$ More specifically, we assume that the opportunistic party wing is responsable for the selection of the party's candidate, so that the party will select the candidate with the largest winning probability in an upcoming election.

In particular, the party has to take the following decision. Suppose that the party is currently the ruling party and that the prime minister can be nominated one more time. Then the party has to decide wether the incumbent is nominated again or whether she should be replaced by a newcomer. Obviously, this decision will depend on the

\footnotetext{
${ }^{11}$ In the model of Roemer (1999), a similar effect arises. He identifies the policy preference of the ideologues with those of the party's average voter. If in his model, say, the left party gained a large majority because even voters to the right of the median voted for the left party, then the ideologue's policy preference would move closer to the median position and the preferences of the opportunists and the ideologues would become more aligned.

${ }^{12}$ In Section 5, we study a version of the model in which voters have heterogeneous policy preferences that can be ordered along the left-right dimension; i.e., there are voters with very leftist or very rightist policy preferences and voters with modest policy preferences. In this extended model, we can provide a foundation of the constraints that are implied by small majorities. There we show that, even if all members of party $L$ belong to the opportunistic wing, it is a best response for them to enact the constraint $p \leq 1$, because otherwise they would lose the support of voters whose preferred policy is very leftist.

${ }^{13}$ The role of parties for the nominations of candidates has been extensively studied by Caillaud and Tirole (2002).
} 
performance of the current prime minister.

We assume that the party members have the same information about the prime minister's competence as the voters. This assumption is consistent with our view of competence as a specific skill that can be demonstrated on the job only; i.e., there is no alternative way of demonstrating that a person would be a competent prime minister.

\subsection{Sequence of events}

We now turn to the dynamics of the model.

We assume that an election period has two time periods; e.g., if there is an election at date $T$, then the next election will be at date $T+2$, so that an election period consists of the time period from date $T$ until date $T+1$ and the time period from date $T+1$ until date $T+2$. A political decision is taken only in the first time period, i.e., in the time period starting at date $T$ but not in the time period starting at date $T+1$.

This assumption is empirically motivated. As the end of the election period approaches, politicians start to prepare the campaign for the upcoming election so that the political activity is reduced. This implies in particular that potential utility gains for the voters are foregone. For instance, a utility gain of $g_{T+1}$ could be realized if there was an election at date $T+1$, but not if there was an election at date $T .{ }^{14}$ As will become clear, this assumption is important for our welfare analysis of early elections, but not for our equilibrium analysis.

The sequence of events related to an election period starting at date $T$ is as follows:

1. Prior to the election at date $T$, both parties nominate a candidate. Also, the utility gain $g_{T}$ from a political decision taken in the time period from $T$ until $T+1$ becomes publicly known.

2. Elections take place, one party wins either with a large or a small majority. This is observed by the voters. The winning party's candidate becomes prime minister.

3. The state of the world in period $T, \omega_{T}$, is realized and observed by the prime minister if and only if she is of the competent type.

4. The prime minister chooses a policy $p_{T}$. Her choice is constrained if the ruling party has a small majority.

5. Prior to date $T+1, g_{T+1}$ becomes publicly known. After date $T+1, \omega_{T+1}$ is observed by a competent prime minister. In the present model with fixed election dates $T$ and $T+2$, this has no bearing on the equilibrium analysis.

6. Voters realize the utility generated by the political decision that was taken in the first half of the election period.

\footnotetext{
${ }^{14}$ We do not literally assume that there are no political decisions at all in the second half of the election period, but rather that political activities are reduced.
} 
7. Parties nominate their candidates for the election in $T+2$ and the utility gain $g_{T+2}$ becomes publicly known.

A crucial property of this timeline is that the consequences of political decisions are realized only after some delay. Voters learn in the second half of the election period whether the political decision taken in the first half of the election period was a good decision, in the sense of leading to a small value of the loss function

$$
\left(\frac{1}{2}+\omega_{T}-p_{T}\right)^{2}
$$

or a bad decision.

The motivation of the assumption that there is a time lag between the choice of policies and the date at which they become effective is as follows. Policy measures are often controversial on the date at which they are taken. However, as time goes by, it becomes clearer whether or not the policy is successful in reaching a given objective; e.g., the reduction of unemployment.

The size of the loss is a signal of the prime minister's competence. For instance, if the loss is equal to zero, this implies that the prime minister is competent with probability 1 , because an incompetent prime minister does not observe $\omega_{T}$ and has a zero probability of picking the policy that matches the state of the world. However, if the loss is not zero, then things are not as clear-cut. For instance, there might be a probability that the prime minister is competent but could not implement the policy that yields to a loss of zero because of a blockade in parliament. In this case, the loss is only a noisy signal about the prime minister's competence, and voters update their beliefs after observing the loss. The equilibrium analysis below will endogenously determine the beliefs of voters.

The information about the success or failure of policy, as measured by the loss function, is available when parties decide about their candidates for the next election. In particular, the ruling party's decision whether or not to nominate an incumbent prime minister a second time is therefore influenced by the size of the loss in the previous period and the voters' assessment of the prime minister's competence.

We assume that this sequence of events is infinitely repeated. This implies that our analysis is not driven by end round effects. Voters and parties are infinitely lived, and future payoffs are discounted according to a discount factor $\delta \in(0,1)$. Given that there is an election at date $T$, the expected utility of a voter as of date $T$ is written as

$$
U_{T}=E\left[\delta u_{T}+\delta^{2} U_{T+2}\right]
$$

where $u_{T}$ is the utility from the political decision taken in period $T$ and $U_{T+2}$ is the expected life-time utility at the date of the next election. Likewise, the preferences of the opportunists in party $j$ are given as

$$
V_{T}^{j}=E\left[(1+\delta) v_{T}^{j}+\delta^{2} V_{T+2}^{j}\right]
$$


where $v_{T}^{j}=1$ if party $j$ is the ruling party over an interval from $T$ until $T+1$, and $v_{T}^{j}=0$ otherwise.

$E$ denotes an expectations operator. Expectations are taken with respect to future political events which in turn depend on the time series properties of the primitives $g_{T}$ and $\omega_{T}$. For simplicity, we assume that $\left(g_{T}\right)_{T=0}^{\infty}$ is a sequence of independent and identically distributed random variables with support $[0, \bar{g}]$ and expected value $g^{e}$. $\left(w_{T}\right)_{T=0}^{\infty}$ is also a sequence of independent and identically distributed random variables that are uniformly distributed over the unit interval.

\subsection{Equilibrium Analysis}

We now turn to the analysis of the equilibria of the game. The solution concept is Perfect Bayesian Equilibrium which requires that the strategies of voters, parties and the prime minister are mutually best responses for given beliefs about the prime minister's competence and that beliefs are derived from Bayes' rule whenever possible. We also impose a condition of stationarity so that equilibrium play is the same for two subhistories of the game that differ only in calendar time. Also, we omit time indices if this creates no confusion.

Finally, we need some assumptions on voting behavior. Generally, game-theoretic treatments of voting decisions give rise to multiple Nash equilibria. For instance, if almost everyone votes for party $L$, then a single individual may vote for either party because he cannot influence the outcome of the election anyway. Hence, there is both a Nash equilibrium where this voter votes for party $L$ and a Nash equilibrium where he votes for party $R$.

In elections with only two possible outcomes, e.g., a victory for $L$ versus a victory for $R$, only one of those many equilibria survives the elimination of weakly dominated strategies. In our model, however, a voting decision has four possible outcomes (a large majority for $L$, a small majority for $L$, a large majority for $R$ or a small majority for $R$ ) so that we cannot rely on the elimination of dominated strategies. We therefore impose the following assumptions on the voting behavior of individuals.

Assumption 1 If a large majority for one of the parties is the best outcome from the perspective of voters, then every voter votes for this party.

Assumption 1 implies that voters manage to coordinate in such a way that their preferred equilibrium results. For instance, if all voters prefer a large majority for $R$ over a small majority for $R$, a large majority for $L$, and a small majority for $L$, then the assumption says that all voters vote for party $R$ and, as a result, that the majority for party $R$ will be large.

Assumption 2 If all voters are indifferent between a large majority for $L$ and a large majority for $R$ as well as between a small majority for $L$ and a small majority for $R$, 
then each voter votes for party $L$ with probability $\frac{1}{2}$.

Assumption 2 concerns a situation where voters have no preference for either of the parties. In this case, it is assumed that each voter votes with equal probability for either party. Since the number of voters is large, the law of large numbers implies that the vote shares of the parties will almost surely be very close. Hence, a situation where all voters are indifferent leads with probability $\frac{1}{2}$ to a small majority for $L$, and with with probability $\frac{1}{2}$ to a small majority for $R$.

Proposition 1 Under Assumptions 1 and 2, there is a stationary perfect Bayesian equilibrium with the following properties:

- Policy Outcomes: If the prime minister is incompetent, then the policy outcome is $p=1$. If the prime minister is competent, then the policy outcome is $p=\frac{1}{2}+\omega$, if there is no political blockade, and $p=1$, otherwise.

- Nomination Decisions: The ruling party in $T$ nominates the prime minister for the election in $T+2$ only if $p_{T}=\frac{1}{2}+\omega_{T}$, i.e., and only if she has proven to be competent.

- Election Outcomes: The prime minister runs for a second term only if she has proven to be competent. In this case her party wins a large majority. Otherwise, both parties nominate a newcomer, and the outcome is a small majority for $L$ or a small majority for $R$, with equal probability.

The prime minister always has an incentive to move as close to the voters' ideal policy as possible. If she is in her second and last term office motivations do no longer play a role so that she chooses the policy that is best for voters. If she is in her first term she can achieve a second nomination only if the policy matches the state of the world, so that $p=p^{*}$. If this outcome is out of reach because of a lack of competence or a blockade, she makes the proposal that is best for the voters under these circumstances, $p=1$.

If the prime minister has proven to be capable of generating high utility for voters, i.e., if $p^{*}$ has been implemented, then voters will reward this ability with a large majority in the subsequent election. This implies that the prime minister will be nominated for a second term because the party's main motivation is to rule as often as possible. Finally, given that the prime minister's majority is large, she will no longer have to compromise with the ideological party wing.

By contrast, if the previous policy was $p=1$ then the ruling party nominates a newcomer to avoid a large majority for the opposition party. The logic is as follows: the outcome $p=1$ may either be due to a blockade or due to the prime minister's lack of competence. If previously there was a blockade, nothing can be learned from the policy outcome so that the posterior belief on the prime minister's competence, 
conditional on a blockade, is equal to the prior belief of $\frac{1}{2}$. If there was no blockade, then the conditional probability that the prime minister is competent equals 0. Hence, the probability that the prime minister is competent, conditional on $p=1$, is bounded from above by $\frac{1}{2}$. Now suppose the prime minister would run against a newcomer from the opposition party. The newcomer's probability of competence is equal to $\frac{1}{2}$ and, moreover, he is able to deliver the good outcome $p^{*}$ in two subsequent periods, which would be the unique Pareto-dominant outcome. As a consequence, even if the prime minister and the newcomer had the same probability of being competent, the voters would prefer the newcomer because he is younger. Therefore the opposition party's candidate would be strictly preferred by the voters and win with a large majority.

The equilibrium characterized in Proposition 1 is not unique. However, it is the one we are interested in because of the consequences of a political blockade: First, a competent prime minister has no way of distinguishing herself from an incompetent one and will not be rewarded with a second term. Second, voters cannot realize the gains from having a competent prime minister.

\section{Early elections}

We now extend the model of the previous section and assume that the prime minister has the option to call for an early election in $T+1$. In such an early election, the prime minister will compete against a newcomer from the opposition party.

Given our assumption that a politician can run only twice, early elections are costly in the sense that they reduce a prime minister's maximal time in office from four time periods to three periods. ${ }^{15}$ However, we have seen in the previous section that in case of a political blockade a prime minister will be replaced by a newcomer after two periods. Consequently, a call for early elections is an attractive option for the prime minister if she can thereby get three instead of two periods.

We assume that the prime minister decides on early elections based on the public opinion about the competence of the government and the opposition party. In a perfect Bayesian equilibrium, the beliefs about the prime minister's competence at the date of an early election are pinned down by Bayes' rule. For the opposition party, we model the competence assessment as a probability $k$ that the party's candidate in an early election would be competent. $k$ is publicly observable. For simplicity, $k$ can only take two values, $k_{L}$, and $k_{H}$, with equal probability. For ease of exposition, we assume that $k_{L}=\frac{1}{6}$, and $k_{H}=\frac{5}{6} \cdot{ }^{16}$ As will become clear, $k_{L}=\frac{1}{6}$ implies that, at the date of an early election, the probability that the prime minister is competent is twice the

\footnotetext{
${ }^{15}$ This assumption is not essential for the main results. We also analyzed a specification of the model where candidates may also run in the regular election following an early election. In this case, early elections make it possible to expand the maximal time in office from four time to five periods. The qualitative results do not depend on this modelling choice.

${ }^{16}$ There exist critical values $\hat{k}_{L}$ and $\hat{k}_{H}$ such that our results go through, whenever $k_{L} \leq \hat{k}_{L}$ and $k_{H} \geq \hat{k}_{H}$. A characterization of these critical values is straightforward, but requires lengthy derivations.
} 
probability that that the opposition party's candidate is competent, given that the opposition party is weak.

Empirically, there is always survey data available that gives the standing of the ruling party relative to the opposition party. We think of $k=\frac{1}{6}$ as indicating a situation where the opposition party is weak. For instance, suppose that the opposition party does not currently have a strong leader and that a call for early elections implies that the opposition party has less time for the nomination process than in a regular election. ${ }^{17}$

Figure 1: Sequence of events with early elections

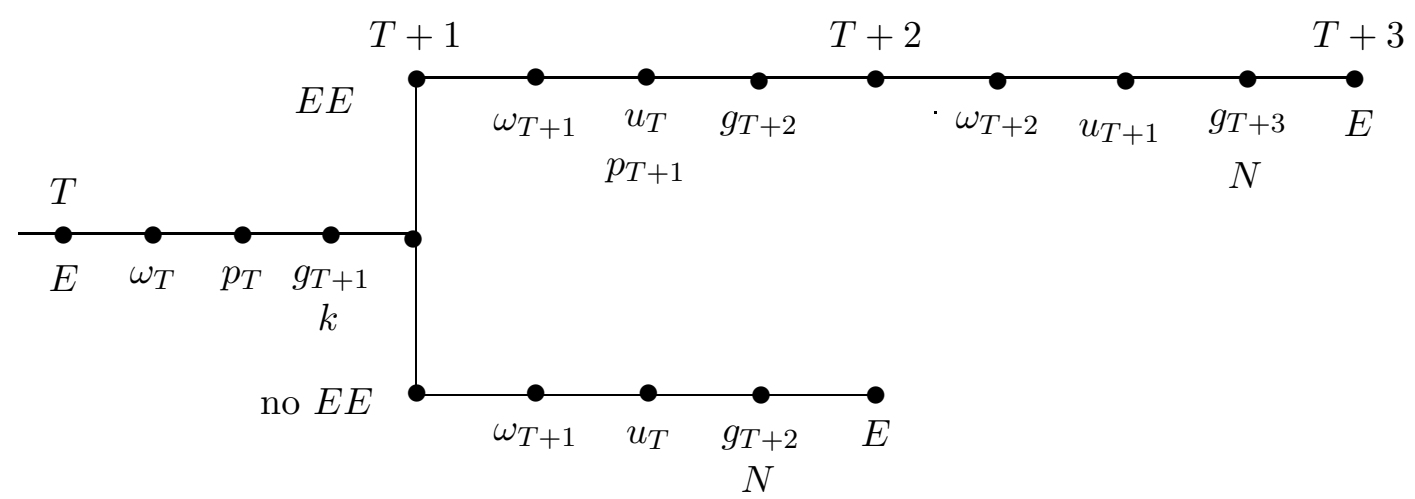

$E$ indicates dates at which regular elections take place. At date $T+1$, the prime minister decides whether or not to have an early election. The figure also illustrates the flow of information, i.e., the dates at which the values of $\omega$ and $g$ are drawn, the dates at which political decisions are taken, $p$, and the dates at which the consequences of the decisions are realized, $u$. Finally, the letter $N$ marks the dates at which parties decide about the nomination of candidates.

Figure 1 illustrates the sequence of events if early elections are possible. At date $T$, there is a regular election. Prior to date $T+1, k$ is observed. Based on this information the prime minister decides whether early elections $(E E)$ take place. The figure also shows that an early election changes the sequence of dates at which political decisions are taken, and thereby also the sequence of utility realizations. For instance,

$$
u_{T+1}= \begin{cases}0, & \text { if } \quad \text { no } E E \text { in } t+1, \\ g_{T+1}-\left(\frac{1}{2}+\omega_{T+1}-p_{T+1}\right)^{2}, & \text { if } E E \text { in } t+1 .\end{cases}
$$

Proposition 2 There exists a cutoff-value $\hat{\delta}$, so that for all $\delta \leq \hat{\delta}$ there is a stationary perfect Bayesian equilibrium with the following properties:

- Policy Outcomes, Nomination Decisions, and the outcome of regular elections are as in Proposition 1.

\footnotetext{
${ }^{17}$ Smith (2004) analyzes early elections in the United Kingdom and comes to the conclusion that the weakness of the opposition party is a necessary condition for an early election: "(...) early elections are between incompetent governments and ill prepared challengers" (p. 61).
} 
- Early Elections: there are early elections if and only if $k=\frac{1}{6}$, and the prime minister is incompetent or there is a political blockade. The prime minister's party wins and gets a large majority.

The equilibrium is such that both a competent prime minister who faces a blockade and an incompetent prime minister initiate early elections if the opposition party is weak. They can thereby avoid being replaced by a newcomer in $T+2$ and stay in office until $T+3$.

The intuition for this result is as follows: If a prime minister is blocked she cannot prove her competence prior to the next regular election. She may, however, call for an early election and hope that voters are sufficiently confident that she is competent and reelect her. However, the consequences of political decisions are realized only after some delay. This creates an incentive for an incompetent prime minister to prolong her government by imitating a competent one who calls for early elections. Early elections are thus initiated by every incompetent prime minister and by the competent ones who are blocked. Consequently, the probability that the prime minister is competent is lower in an early election than in a regular election with two newcomers. Formally, Bayes' rule implies that conditional on early election taking place, the probability that the incumbent is competent equals

$$
\frac{\operatorname{Pr}\{t=c, \text { blockade }\}}{\operatorname{Pr}\{t=c, \text { blockade }\}+\operatorname{Pr}\{t=i\}}=\frac{\frac{1}{2} \times \frac{1}{2}}{\frac{1}{2} \times \frac{1}{2}+\frac{1}{2}}=\frac{1}{3} .
$$

This is larger than $\frac{1}{6}$ so that the prime minister is more likely to be competent than the newcomer and wins with a large majority if the opposition party is weak. ${ }^{18}$

The existence of the equilibrium in Proposition 2 requires that the discount factor $\delta$ does not exceed a threshold level $\hat{\delta}$. This is due to the fact that in an early election the prime minister can run for only one additional legislative period and the newcomer can run for two legislative periods. Hence, if both candidates were equally likely to be competent, the newcomer would be more attractive for the voters because, in case of being competent, the latter can deliver the good outcome $p^{*}$ twice. If $\delta$ is low enough, then the prime minister's competence advantage dominates this effect so that she will win in an early election.

There are other stationary perfect Bayesian equilibria than the one described in Proposition 3. Most importantly, the equilibrium without early elections that has been characterized in Proposition 1 survives the modification of the model.

Proposition 3 For all $\delta$, there is a stationary perfect Bayesian equilibrium such that the prime minister never calls for early elections. Nomination decisions and policy outcomes and the outcome of regular elections are as in Proposition 1.

\footnotetext{
${ }^{18}$ In Section 5, we study an extended model that has probabilistic voting results and in which an early election may be lost by the incumbent.
} 
If the voters interpret an early election as indicating that the prime minister is incompetent, then the prime minister has no incentive to initiate them because she would lose her office otherwise. Consequently, neither an incompetent prime minister nor a blocked prime minister opts for early elections.

It is straightforward to show that there is no equilibrium that has political blockades and in which the use that is made of early elections distinguishes an incompetent prime minister from a blocked competent one. Formally, there is no equilibrium that is fully separating, in the sense that the action "early elections" is chosen only by a competent or an incompetent type. Suppose, for instance, that only competent prime ministers call for early elections. In such an equilibrium, conditional on an early election taking place, voters would know that the prime minister is competent and reelect her. But then the incompetent type would have an incentive to mimic the competent type and also initiate an early election. Otherwise her incompetence would be revealed prior to the next regular election and she would not get a second nomination. With similar arguments, we can show that there is no equilibrium in which only an incompetent prime minister initiates early elections. This contradicts the existence of a separating equilibrium. We summarize this reasoning in the following Proposition.

Proposition 4 There is no equilibrium in which early elections occur and in which the decision to initiate an early election fully reveals the prime minister's type.

This result implies that there is no objective criterion that would make it possible to distinguish an early election that is beneficial for voters (because the current prime minister is competent and should be given the chance to enlarge her support in parliament) from one that has detrimental consequences (because an incompetent prime minister can gain additional time in office).

In Germany, for instance, the federal president is asked to decide whether an early election is legitimate because the stability of government might be endangered. In our model, such a distinction can be made retrospectively, but not at the date of the regular election. It therefore makes no sense to delegate the assessment of an early election to anyone who is an outsider to the political process, such as the supreme court or, in some countries, the president. The remaining alternatives are either a clause that says early elections are generally possible, or a clause that says they are not. In the next section, we compare these two alternatives from a welfare perspective.

\section{Welfare Analysis}

Proposition 4 implies that there are only two consistent ways of treating early elections at the constitutional level, either they are generally possible (as, for instance, in the United Kingdom), or they are generally impossible (as, for instance, in Switzerland and Norway). This raises the question which of these two alternatives is better from the 
perspective of voters.

In the following, we answer this question by means of a comparison of the utility of voters in an equilibrium where early elections are never initiated, as in Proposition 1 , and in an equilibrium where they are initiated by an incompetent or a blocked government whenever the opposition party is weak, as in Proposition 2.

We first compare these equilibria from an ex ante perspective that we define as a situation prior to an election with two newcomers and prior to learning the next period's level of $g$. In the Appendix (Lemma 1) we derive the following expression for voter utility $U^{N}$ in an equilibrium without early elections:

$$
U^{N}=\mu^{N} g^{e}-\nu^{N} \frac{1}{12}
$$

where

$$
\mu^{N}:=\frac{\delta+\frac{1}{4} \delta^{3}}{1-\frac{3}{4} \delta^{2}-\frac{1}{4} \delta^{4}} \quad \text { and } \quad \nu^{N}:=\frac{\frac{3}{4} \delta}{1-\frac{3}{4} \delta^{2}-\frac{1}{4} \delta^{4}} .
$$

$\mu^{N}$ is a weight on the average utility gain from political decisions $g^{e}$ and $\nu^{N}$ is a weight on the average value of the loss function that is implied by an incompetent political decision. ${ }^{19}$ Analogously, we derive the following expression for voter utility $U^{E}$ in an equilibrium with early elections (Lemma 5):

$$
U^{E}=\mu^{E} g^{e}-\nu^{E} \frac{1}{12}
$$

where

$$
\mu^{E}:=\frac{\delta+\frac{3}{8} \delta^{2}+\frac{1}{4} \delta^{3}}{1-\frac{3}{8} \delta^{2}-\frac{3}{8} \delta^{3}-\frac{1}{4} \delta^{4}} \quad \text { and } \quad \nu^{E}:=\frac{\frac{3}{4} \delta+\frac{1}{4} \delta^{2}}{1-\frac{3}{8} \delta^{2}-\frac{3}{8} \delta^{3}-\frac{1}{4} \delta^{4}} .
$$

Straightforward algebraic manipulations establish the following result which we state without proof.

Corollary 1 For all $\delta \in(0,1), \mu^{E}>\mu^{N}$ and $\nu^{E}>\nu^{N}$.

According to Corollary 1, the welfare comparison of the two equilibria gives rise to an urgency versus quality tradeoff. Early elections give more weight both to $g^{e}$, the expected gains from policy-making, and to $\left(-\frac{1}{12}\right)$, the loss due to incompetence of the prime minister. With early elections, there will be more policy decisions. Simultaneously, the average quality of political decisions declines. The latter effect arises because without early elections an incompetent prime minister is replaced by a newcomer after two periods. With early elections, by contrast, she can stay in office for three periods. Given this tradeoff, voters prefer the equilibrium with early elections if and only if the expected gains $g^{e}$ from policy making are sufficiently high. This observation implies that the following corollary holds.

\footnotetext{
${ }^{19}$ To see that the average loss is equal to $\frac{1}{12}$, note that an incompetent prime minister chooses $p=1$ irrespective of the state of the economy and hence creates an expected loss of $\int_{0}^{1}\left(\frac{1}{2}+\omega-1\right)^{2} d \omega=\frac{1}{12}$.
} 
Corollary 2 There is a cutoff value $\hat{g}^{e}$ such that $U^{E}>U^{N}$ if and only if $g^{e}>\hat{g}^{e}$.

We now look at the urgency versus quality tradeoff from an interim perspective. More precisely, we study the following question: suppose that there was a regular election at date $T$ and that the gain from having a political decision in period $T+1, g_{T+1}$, has been revealed. Suppose there is a status quo constitution that does not allow for early elections. Now suppose that the policy in $T$ has been $p_{T}=1$ and that the opposition party is currently weak. Suppose the government initiates a referendum about the question whether the constitution should be changed in such a way that from period $T+1$ on early elections are allowed, with the understanding that this implies that the equilibrium will be as in Proposition 2, i.e., an incompetent or a blocked government calls for early elections whenever the opposition party is weak.

If the status quo constitution prevails, then the utility of voters is $\delta U^{N}$ because there will be a regular election with two newcomers in $T+2$. By contrast, if early elections take place in $T+1$, then the expected utility of voters is

$$
\delta\left(g_{T+1}-\frac{2}{3} \times \frac{1}{12}\right)+\delta^{2} U^{E},
$$

where $\frac{2}{3}$ is the probability that the prime minister is of the incompetent type in an equilibrium with early elections. We obtain the following Corollary that we state without proof.

Corollary 3 There is a cutoff value $\hat{g}$ such that voters are in favor of early elections ex interim if and only if the short run utility gain $g$ from a political decision satisfies $g>\hat{g}$.

Propositions 1 and 3 imply that the welfare comparison of the two equilibria may give rise to a time inconsistency. From an ex ante perspective, it is decisive how large the average utility gain $g^{e}$ from a political decision is. From an interim perspective, it also matters how much utility can be gained in the short run. If the utility gain is small on average, then the voters may prefer to have a constitutional ban on early elections ex ante. However, if ex interim they find themselves in a situation where a lot can be gained, they are willing to abandon this constitution in order to have an election immediately. Moreover, once the possibility of early elections has been established, it will be difficult to remove it again. Politicians benefit from the possibility of early elections and have no reason to seek a further constitutional change, after the political crisis has been overcome. These considerations show that it is difficult to establish a stable constitution, i.e., one that is not bound to be changed, that entirely precludes early elections. 


\section{$5 \quad$ An extended model}

We will now study an extended version of the model in Section 3 and introduce two new elements. First, we introduce heterogeneity among voters. This extension implies that there are indeed voters who benefit from political blockades and whose support is important for the parties. We can thereby endogenize the constraint that a left party does not implement a rightist policy if its majority in parliament is fragile. More formally, we no longer restrict the parties' strategies with respect to the decision whether or not they accept the prime minister's policy proposals and show that the parties have a reason to enact political blockades in equilibrium.

Second, we model election campaigns as a source of randomness such that the outcome of an election is no longer perfectly predictable. For instance, if both parties nominate a newcomer, then there is a probability that one candidate will outperform the other in the pre-election phase and win with a large majority. Also, we assume that voters can choose to abstain from an election. As will become clear, these extensions make our model more realistic in that there are two types of elections. On the one hand, there are elections where it is important for the parties to get enough support from the voters with extreme policy preferences. For instance, if the very leftist voters abstained and the very rightist participated in the election, then party $R$ would win. This creates an incentive for the left party to fight for the votes of the very left. On the other hand, there are races where the focus is on the voters in the middle, and the winning party is successful in getting the support of all voters that are close to the median.

Finally, we show that with probabilistic voting outcomes early elections may be lost by the incumbent. As documented by Smith (2004) early elections are frequently lost by the incumbent, so that it is important for the empirical plausibility of our model that such an event is possible in equilibrium.

Voter utility in period $T$ is now given by

$$
u_{T}(\theta)=g_{T}-\left(\theta+\omega_{T}-p_{T}\right)^{2},
$$

where $\theta \in[0,1]$ is the voter's type. The preferred policy of a type $\theta$ voter is $p^{*}(\theta)=\theta+\omega$.

Assumption 3 The distribution of voter types has full support. Moreover, there is a well-defined political middle that contains a majority of voters: there is $\epsilon<\frac{1}{2}$ such that $1>G\left(\frac{1}{2}+\epsilon\right)-G\left(\frac{1}{2}-\epsilon\right)>\frac{1}{2}$.

Assumption 3 implies that there is a fraction of voters with extreme policy preferences. For instance, the ideal policy of a voter of type 0 is bounded from above by 1, i.e., whatever the state of the economy, a very leftist voter never has an ideal policy, $p^{*}(0)$, that exceeds 1 . In addition, there is a neighborhood of the median voter that contains a majority of voters. If a party succeeds in getting the votes from these voters, then 
it will end up having a large majority in parliament. Moreover, we assume that voters in the middle manage to coordinate if a large majority for one of the parties is their preferred outcome.

Assumption 4 If a large majority for one of the parties is the best outcome from the perspective of all voters with types $\theta \in\left[\frac{1}{2}-\epsilon, \frac{1}{2}+\epsilon\right]$, then all of these voters vote for this party.

We assume that the prime minister's preference has the same structure as in Section 2 , i.e., the prime minister is primarily office-motivated. However, she has a policy motivation that breaks ties between alternatives that have the same implications for office-holding. We assume that her policy preference now coincides with the policy preference of the median voter $\theta=\frac{1}{2}$. The interpretation of this assumption is that even if the prime minister has no need to please the median voter in order to increase her reelection probability, she behaves "opportunistically" in the sense of maximizing the support of her policy proposals in the general public. $^{20}$

Prior to any election there is an election campaign in which one candidate may outperform the other one - in the sense that in the view of the voters he seems to be more likely to be competent - or in which the two candidates tie. The outcome of the election campaign will influence the result of an election and in particular whether the winning party has a large or a small majority.

Formally, we model the outcome of an election campaign as the realization of a random variable $\beta$ which takes values in $\{-1,0,1\}$ and is generated as follows: $\beta=$ $\alpha^{L}-\alpha^{R}$, where $\alpha^{L}$ and $\alpha^{R}$ are independent random variables that take the values 0 and 1 with the following probabilities

$$
\operatorname{Pr}\left(\alpha^{j}=1 \mid t^{j}=c\right)=\operatorname{Pr}\left(\alpha^{j}=0 \mid t^{j}=i\right)=\eta,
$$

where $t^{j} \in\{c, i\}$ is the type of party $j$ 's candidate. We assume that $\eta \in\left(\frac{1}{2}, 1\right)$ so that a competent candidate is more likely to get a good signal, $\alpha^{j}=1$, and an incompetent one is more likely to get a bad signal, $\alpha^{j}=0$. Voters do not observe $\alpha^{L}$ and $\alpha^{R}$. They only get a signal $\beta$ of the relative competence of the candidates. The informational content of $\beta$ depends on the prior beliefs of individuals on a candidate's type. For instance, if two newcomers compete, then both are ex ante equally likely to be of type c. If voters observe that $\beta=1$, then the conditional probability that the candidate from party $L$ is competent exceeds the conditional probability that the candidate from party $R$ is competent. If $\beta=0$, then both are equally likely to be of type $c$, etc.

\footnotetext{
${ }^{20}$ Given that the median voter's preferred policy is a unique Condorcet winner, we can define opportunism equivalently as the objective to minimize the number of voters who prefer an alternative policy over the policy proposal of the prime minister.
} 
The extended model can be solved analytically. ${ }^{21}$ However, for ease of exposition we impose in the following the assumptions that $\delta=\frac{1}{2}$ and $\eta=\frac{3}{4}$. This allows us to use numerical methods - as opposed to lengthy algebraic manipulations of inequalities - in order to illustrate the properties of the equilibria we are analyzing.

For the same reasons as in the previous section, a constitution that enables a prime minister to initiate early elections in the middle of a legislative period gives rise to multiple equilibria. The following Proposition characterizes an equilibrium, where early elections do never arise. In this equilibrium, voters would interpret an early election as indicating that the prime minister must be incompetent so that the prime minister would lose with probability 1 .

Proposition 5 Let $\delta=\frac{1}{2}$ and $\eta=\frac{3}{4}$. Under Assumptions 2, 3, and 4, there is a stationary perfect Bayesian equilibrium with the following properties:

- Political Blockades: If Party $L(R)$ has a small majority it accepts the prime minister's policy proposal if and only if $p \leq 1(p \geq 1)$. Otherwise it accepts any policy proposal.

- A prime minister never initiates early elections. Policy Outcomes and Nomination Decisions are as in Proposition 1.

- Elections: The prime minister runs for a second term only if she has implemented $p^{*}\left(\frac{1}{2}\right)=\frac{1}{2}+\omega$. In this case her party wins with a large majority. If both parties nominate a newcomer, then the outcome is a small majority for $L$ or a small majority for $R$, with equal probability, if $\beta=0$. If $\beta=1$, party $L$ wins with a large majority and if $\beta=-1$ party $R$ wins with a large majority.

Proposition 5 establishes that political blockades are part of an equilibrium with heterogeneous voters. Otherwise, it establishes the same results as Proposition 1, except that there is a richer set of election outcomes: An election where both parties nominate a newcomer does not necessarily have a winning party with a small majority. If one candidate appears superior in the election campaign, her party will win with a large majority.

The fact that voter preferences are heterogeneous implies that there are indeed voters who benefit from a political blockade. Figure 3 shows the voter types who prefer a small majority over a large majority for party $L$. These voters have extreme policy preferences and hence prefer the constraint $p \leq 1$ to be in place.

Given the preferences of voters, we can explain the parties' behavior when deciding about the prime minister's policy proposals and, in particular, why small majorities give rise to political blockades. The formal proof in the Appendix uses standard folk

\footnotetext{
${ }^{21}$ In the appendix, we explicitly derive all expressions that are relevant for a characterization of equilibrium.
} 
Figure 2: A large majority for $L$ vs a small majority for $L$



$L^{l c}(\theta)$ is the expected utility of voter type $\theta$ conditional on a large majority for the left party and a competent prime minister. $L^{s c}(\theta)$ is expected utility conditional on a small majority and a competent prime minister. A small majority implies that the prime minister cannot choose policies $p>1$.

theorem arguments to establish that the left party will enforce the constraint $p \leq 1$ whenever it has only a small majority in parliament: If a deviation from $p \leq 1$ implied that the very left voters would abstain in future elections and that the right party would therefore become more likely to win, then it is a best response for the party not to accept any policy proposal $p>1$.

The interpretation of this result is that the left party has an implicit contract with the leftist voters. If the left party came into power only because of the support of the very left and then implemented a policy that is good for the voters in the middle but bad for the very left, then the latter will no longer support the left party. In the long run, this has detrimental consequences for party $L$ so that it wants to honor this implicit contract.

A similar argument can be used to show that, whenever the left party has a large majority, it seeks to move as close to the median voter's ideal policy as possible. If party $L$ won a large majority because it got all the voters in the middle and then implemented partisan policies that would benefit only the very left, then the voters in the middle would respond to this breach of contract by switching to party $R$ in future elections.

We now show that there is also an equilibrium that is an analogous to Proposition 2. In particular, a competent prime minister who is blocked and an incompetent prime minister call for early elections whenever the opposition party is weak.

Proposition 6 Let $\delta=\frac{1}{2}$ and $\eta=\frac{3}{4}$. Under Assumptions 2, 3, and 4 there is a stationary perfect Bayesian equilibrium with the following properties:

- Political Blockades, Policy Outcomes, Nomination Decisions, and the outcome of regular elections are as in Proposition 5.

- Early Elections: There are early elections in $T+1$ if and only if the preceding 
history is as follows. In $T$ there is a regular election with two newcomers, which ends with a small majority, $\beta=0$. Moreover, the opposition party is weak, $k=\frac{1}{6}$, and the prime minister is incompetent or there is a political blockade. Suppose the prime minister belongs to party $L(R) . L(R)$ wins and gets a large majority only if $\beta=0$, or $\beta=1(\beta=-1)$. Otherwise the opposition party wins and gets a large majority.

Proposition 6 extends Proposition 2 to a model with heterogeneous voters and probabilistic election outcomes. In particular, the prime minister may lose in an early election. It is rational for her ex ante to call for an early election because she is likely to win. Ex post, however, she may regret this choice. If the candidate of the opposition party outperforms the prime minister in the election campaign, then indeed the former will win. Formally, if the prime minister belongs to party $L$ and the election campaign has $\beta=-1$, then the posterior beliefs of the voters are such that the candidate from party $R$ is more likely to be competent.

Moreover, after an early election there is always a large majority for the ruling party. Hence, early elections make it possible to overcome a political blockade. The reason is that, for voters in the middle, a large majority for the party with the more competent candidate is their preferred outcome. By assumption, these voters form a large majority so that their preferred outcome prevails.

\section{Welfare Analysis}

We now generalize the welfare analysis that we conducted for the basic model in Section 4. In particular, the extended model makes it possible to answer two additional questions: (i) how does the preference for early elections depend on a voter's type and (ii) what are plausible magnitudes for the advantages and disadvantages of early elections?

In the Appendix, we solve for the expected utility of a voter with type $\theta$ in an equilibrium without early elections, $U^{N}(\theta)$, and in an equilibrium with early elections, $U^{E}(\theta)$, from an ex ante perspective. Again we can decompose these expressions into an urgency and a quality measure and write,

$$
U^{N}(\theta)=\bar{\mu}^{N} g^{e}-\bar{\nu}^{N}(\theta) \text { and } U^{E}(\theta)=\bar{\mu}^{E} g^{e}-\bar{\nu}^{E}(\theta) .
$$

Using numerical methods, ${ }^{22}$ we can show that for $\delta=\frac{1}{2}$ and $\eta=\frac{3}{4}$,

$$
\bar{\mu}^{E}>\bar{\mu}^{N} \text { and } \bar{\nu}^{E}(\theta)>\bar{\nu}^{N}(\theta) \text {, for all } \theta .
$$

This implies that the urgency versus quality tradeoff that we derived for the basic model in Section 4 carries over to the extended model. Early elections lead more frequently to political decisions but also to a lower quality of politicians.

Our answer on the question how different voter types assess this trade-off is based on the observation that $\bar{\nu}^{E}(\theta)-\bar{\nu}^{N}(\theta)$ is an increasing function of $\left|\theta-\frac{1}{2}\right|$. Hence,

\footnotetext{
${ }^{22}$ See Figure 3 below.
} 
the quality disadvantage that is implied by early elections becomes stronger the further away a voter's type is from the median. This is a consequence of the quadratic loss term in the utility function. Large deviations from a voter's ideal policy get more weight. Since equilibrium policy is oriented towards the median, utility losses are more pronounced for voters with extreme policy preferences. In particular, this implies that if the median voter prefers a constitutional ban on early elections, then every other voter shares this preference. Put differently, a constitutional ban on early elections is Pareto-preferred over a constitution that makes early elections possible if and only if it is preferred by the median voter.

The following graph shows the utility difference $U^{N}(\theta)-U^{E}(\theta)$ under the assumption that $g^{e}=\frac{1}{16}$. Given this value, almost every voter type, with the exception of those in a small neighborhood of the median, would prefer a constitution that precludes early elections.

Figure 3: Utility without early elections vs utility with early elections

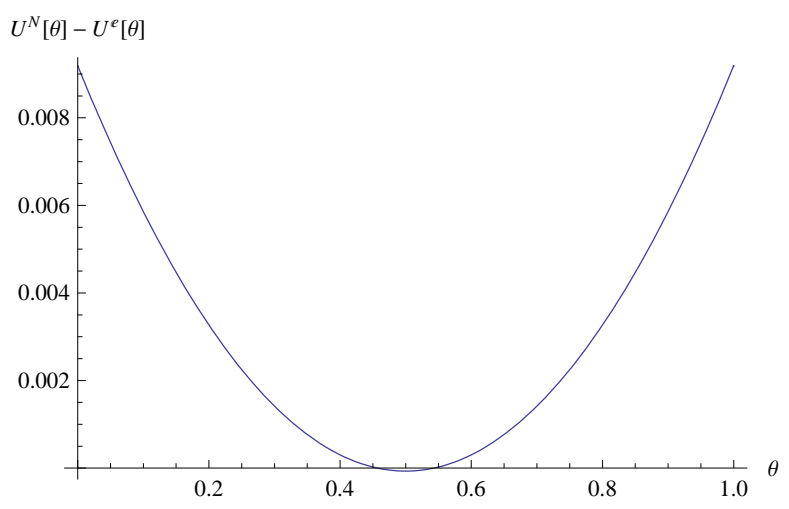

$U^{N}(\theta)$ is the expected utility of voter type $\theta$ from an ex ante perspective in an equilibrium without early elections. $U^{E}(\theta)$ is expected utility in an equilibrium with early elections. The graph is drawn under the assumption that $g^{e}=\frac{1}{16}$.

Given the specification of our model, it is reasonable to assume that $0 \leq g^{e} \leq \frac{1}{12}$. The assumption $g^{e} \geq 0$ implies that, on average, a competent political decision that maximizes the median voter's utility, $p=p^{*}\left(\frac{1}{2}\right)$, is better for the median than not having a political decision which would yield a payoff of 0 . The assumption $g^{e} \leq \frac{1}{12}$ implies that, on average, an uninformed political decision, $p=1$, is bad for the median in the sense of yielding a utility level that is below 0 .

The assumption that $g^{e} \leq \frac{1}{12}$ implies that the very leftist and the very rightist voters are better off in the equilibrium without early elections. We can thus conclude that one has to assume implausibly high values of $g^{e}$ to arrive at the conclusion that it is in the interest of all voters to have a constitution with early elections. For the median voter, the result is not as clear-cut. Approximatively, the median voter prefers the equilibrium with early elections if $g^{e} \geq \frac{1}{16}$ and prefers the equilibrium without early 
elections otherwise. ${ }^{23}$

These considerations can be summarized as follows. Only the case where $g^{e} \leq \frac{1}{16}$ allows for a ranking of alternatives according to the Pareto-criterion. In this case, all voters are, from an ex ante perspective, against a constitution with early elections. For $\frac{1}{12} \geq g^{e} \geq \frac{1}{16}$, voters in the middle want to have early elections and voters with extreme policy preferences oppose them.

\section{Concluding Remarks}

We provided a formal analysis of the advantages and disadvantages of early elections in a model of political competition between a left-wing and a ring-wing party. If the ruling party has only a small majority in parliament, then the government may be unable to implement the policies that would be beneficial to a majority of voters. The government may therefore initiate an early election in order to get a broader support for its agenda.

Our analysis has investigated the consequences of early elections in comparison to an alternative constitution under which early elections are not possible. It has been shown that this comparison reveals an urgency versus quality tradeoff. Early elections make it possible to implement policies that otherwise could not be chosen and this is beneficial from the perspective of voters. On the other hand, early elections enable politicians who do not have a promising agenda to gamble for additional time in office, and this is detrimental from the perspective of voters. An assessment of this tradeoff depends on the utility gain that voters realize, on average, from the political decisions that are made possible if early elections take place.

However, an ideal political constitution in our model would be such that whether or not an early election can take place depends on the importance of the political decisions that currently have to be taken. If, for instance, a war is taking place, then it may be more urgent to overcome a political crisis than otherwise.

Our model does not allow such conditioning on political circumstances. Either early elections can always take place or they are entirely excluded. We think this is a realistic approach with respect to real-world constitutions. Moreover, it is questionable whether, in a richer model, it would be desirable to condition the availability of early elections on the need to overcome a political crisis. This need can be manipulated by the politicians themselves, both in terms of rhetoric and political actions. For instance, prior to the early election in Germany in 2005, it was argued that the importance of a labor market reform and, generally, a better macroeconomic performance made a further phase of political stagnation untenable. After the election, however, the political agenda had changed and, if anything, the labor market reforms that had been initiated prior to the early election were rolled back. Moreover, the moral hazard problem may be more drastic, if instead of adjusting its rhetoric, a government chooses actions (or remains

\footnotetext{
${ }^{23}$ If we assume that, on average, $p=p^{*}\left(\frac{1}{2}\right)$ is beneficial for all voters with types $\theta \in\left[\frac{1}{4}, \frac{3}{4}\right]$, but harmful for all voters with more extreme policy preferences, this implies that $g^{e}=\frac{1}{16}$.
} 
inactive) so that a country's situation becomes sufficiently bad and then tries to take advantage of an early election.

\section{References}

Balke, N. (1990). The rational timing of parliamentary elections. Public Choice, 65:201216.

Caillaud, B. and Tirole, J. (2002). Parties as political intermediaries. Quarterly Journal of Economics, 117:1453-1489.

Chapell, D. and Peel, D. (1979). On the political theory of the business cycle. Economics Letters, 2:327-332.

Diermeier, D. and Merlo, A. (2000). Government turnover in parliamentary democracies. Journal of Economic Theory, 94:46-79.

Kayser, M. (2005). Who surfs, who manipulates? the determinants of opportunistic election timing and electorally motivated economic intervention. American Political Science Review, 99:17-28.

Keppo, J., Smith, L., and Davydov, D. (2007). Optimal electoral timing: Exercise wisely and you may live longer. Review of Economic Studies, forthcoming.

Lächler, U. (1982). On political business cycles with endogenous election dates. Journal of Public Economics, 17:111-117.

Lupia, A. and Strom, K. (1995). Coalition termination and the strategic timing of parliamentary elections. American Political Science Review, 89:648-665.

Roemer, J. (1999). The democratic political economy of progressive taxation. Econometrica, 67:1-19.

Smith, A. (1996). Endogenous election timing in majoritarian parliamentary systems. Economics and Politics, 8:85110.

Smith, A. (2004). Election Timing. Cambridge University Press.

\section{A Proofs of the Propositions in Sections 2 and 3}

\section{A.1 Proof of Proposition 1}

The proof proceeds in two steps. We first derive an expression for the expected utility of voters in the hypothesized equilibrium (Lemma 1). Subsequently, we verify the claims made in Proposition 1 (Lemmas 2-4). 
Lemma 1 Suppose that Proposition 1 is true. Then the expected utility, $U^{N}$, of a voter prior to an election where both parties are nominating a newcomer and prior to learning the next period's $g$ equals

$$
U^{N}=\frac{\left(\delta+\frac{1}{4} \delta^{3}\right) g^{e}-\frac{3}{4} \delta \frac{1}{12}}{1-\frac{3}{4} \delta^{2}-\frac{1}{4} \delta^{4}}
$$

Proof Since both parties have an equal winning probability if they both nominate a newcomer,

$$
U^{N}=\frac{1}{2} U^{N L}+\frac{1}{2} U^{N R}
$$

where $U^{N j}$ is expected utility conditional on a victory of party $j \in\{L, R\}$. Since the prime minister is competent with probability $\frac{1}{2}$,

$$
U^{N j}=\frac{1}{2} U^{N j c}+\frac{1}{2} U^{N j i}
$$

where $U^{N j t}$ is expected utility conditional on a victory of party $j$ and prime minister type $t \in\{c, i\}$. Since a type $i$ prime minister chooses $p=1$ and is not nominated again,

$$
\begin{aligned}
U^{N j i} & =\delta g^{e}-\delta \int_{0}^{1}\left(\frac{1}{2}+w-1\right)^{2} d w+\delta^{2} U^{N} \\
& =\delta\left(g^{e}-\frac{1}{12}\right)+\delta^{2} U^{N}
\end{aligned}
$$

for each $j$.

Now suppose that the prime minister is competent and belongs to party $L$. Then, if $\omega \geq \frac{1}{2}$ the policy is $p=1$ and the subsequent election is one with two newcomers. If $\omega \leq \frac{1}{2}$, then $p=p^{*}$ and the prime minister can prove that she is competent. She will thus be nominated again and gain a large majority implying that

$$
\begin{aligned}
U^{N L c}= & \delta g^{e}+\frac{1}{2}\left(\delta^{3} g^{e}+\delta^{4} U^{N}\right) \\
& +\int_{\frac{1}{2}}^{1}\left\{-\delta\left(\frac{1}{2}+w-1\right)^{2}+\delta^{2} U^{N}\right\} d w \\
= & \delta g^{e}+\frac{1}{2}\left(\delta^{3} g^{e}+\delta^{4} U^{N}\right)+\frac{1}{2}\left(-\delta \frac{1}{12}+\delta^{2} U^{N}\right) .
\end{aligned}
$$

Along the same lines we derive that

$$
U^{N L c}=U^{N R c} .
$$

Equations (4)-(8) imply equation (3).

Lemma 2 Suppose that the ruling party nominates the prime minister for a second election only if she previously generated the outcome $p=p^{*}$. Then, the policy outcome in any period is $p^{*}$ if the prime minister is competent and if there is no blockade, and $p=1$ otherwise.

Proof First, suppose the prime minister is in her last term so that she chooses policy in order to maximize the voters' utility. An incompetent prime minister cannot condition on the current value of $\omega$, and chooses $p$ in such a way that the voters expected utility is maximized. 
A competent prime minister can observe $\omega$ and moves as close to the voters ideal policy as possible. This yields $p^{*}$ if there is no blockade and $p=1$ otherwise. Now consider a prime minister in his first term. She can ensure a second nomination only if she is competent and there is no blockade and if she proposes $p_{T}=p_{T}^{*}$. In all other cases she will not be nominated again and the best admissible policy for voters is $p_{T}=1$.

Lemma 3 Suppose a candidate has already proven to be competent and competes against a newcomer. Then the competent candidate is nominated by her party and wins with a large majority.

Proof From the perspective of voters, large majorities are always preferred over small majorities because they do not give rise to political blockades. Hence, we only need to show that all voters prefer the outcome "large majority for the competent candidate" over the outcome "large majority for the newcomer". If the competent candidate gains a large majority, this yields an expected utility of $\delta g_{T}+\delta^{2} U^{N}$ for the voters. If the newcomer gains a large majority, then the expected utility of voters is

$$
\delta g_{T}+\frac{1}{2}\left(-\delta \frac{1}{12}+\delta^{2} U^{N}\right)+\frac{1}{2}\left(\delta^{3} g^{e}+\delta^{4} U^{N}\right)
$$

It is straightforward to show that this expression is smaller than $\delta g_{T}+\delta^{2} U^{N}$, for all $\delta \in(0,1)$. Hence, a large majority for the competent candidate is the unique Pareto-dominant outcome and she will win a large majority. This is the preferred outcome of her party so that she will be nominated.

Lemma 4 In a perfect Bayesian equilibrium, a prime minister whose party had a small majority in the previous period is nominated for a second term if and only if $p=p^{*}$ in the previous period.

Proof Suppose to the contrary that there is a perfect Bayesian equilibrium such that a prime minister whose party had a small majority in the previous period is nominated for a second-term even though $p=1$. We will show that this leads to a contradiction, because, under Assumption 1 , all voters will vote for the newcomer so that the ruling party would be better off if it also nominated a newcomer.

Suppose first that there was no blockade in the previous period. Consequently, it must be true that the ruling party's candidate is of type $i$. If she is reelected, the expected utility of voters, conditional on "no blockade", is

$$
\delta g_{T}-\delta \frac{1}{12}+\delta^{2} U^{N}
$$

irrespective of whether the majority is large or small. If the newcomer is elected with a large majority, the expected utility of voters is

$$
\delta g_{T}+\frac{1}{2}\left(-\delta \frac{1}{12}+\delta^{2} U^{N}\right)+\frac{1}{2}\left(\delta^{3} g^{e}+\delta^{4} U^{N}\right)
$$

It is straightforward to verify that this exceeds the expected utility if the candidate of the ruling party wins and also the utility that could be realized with a small majority for the newcomer. 
Now suppose that there was a blockade in the previous period. Hence, the ruling party's candidate is of type $c$ with posterior probability $\frac{1}{2}$. Since voters prefer large majorities over small majorities we only need to show that, conditional on a blockade, a large majority for the newcomer Pareto-dominates a large majority for the prime minister, i.e.,

$$
\delta g_{T}+\frac{1}{2}\left(-\delta \frac{1}{12}+\delta^{2} U^{N}\right)+\frac{1}{2}\left(\delta^{3} g^{e}+\delta^{4} U^{N}\right)>\delta g_{T}-\frac{1}{2} \delta \frac{1}{12}+\delta^{2} U^{N}
$$

It is straightforward to show that this holds for all $\delta \in(0,1)$.

\section{A.2 Proof of Proposition 2}

The proof proceeds in two steps. We first derive an expression for the expected utility of voters in the hypothesized equilibrium (Lemma 5). Subsequently, we verify the claims made in Proposition 2 (Lemmas 6-15).

Lemma 5 Suppose that Proposition 1 is true. The expected utility, $U^{E}$, of a voter in an equilibrium with early elections prior to an election where both parties are nominating a newcomer and prior to learning the next period's $g$ equals

$$
U^{E}=\frac{g^{e}\left(\delta+\frac{3}{8} \delta^{2}+\frac{1}{4} \delta^{3}\right)-\frac{1}{12}\left(\frac{3}{4} \delta+\frac{1}{4} \delta^{2}\right)}{1-\frac{3}{8} \delta^{2}-\frac{3}{8} \delta^{3}-\frac{1}{4} \delta^{4}} .
$$

Proof Since both parties have an equal winning probability if they both nominate a newcomer,

$$
U^{E}=\frac{1}{2} U^{E L}+\frac{1}{2} U^{E R}
$$

where $U^{E j}$ is expected utility conditional on a victory of party $j \in\{L, R\}$. Since the prime minister is competent with probability $\frac{1}{2}$,

$$
U^{E j}=\frac{1}{2} U^{E j c}+\frac{1}{2} U^{E j i}
$$

where $U^{E j t}$ is expected utility conditional on a victory of party $j$ and prime minister type $t \in\{c, i\}$. A type $i$ prime minister chooses $p=1$ and initiates early elections whenever $k=\frac{1}{6}$. Otherwise she stays in office until $T+2$, where she is not nominated again,

$$
U^{E j i}=\delta\left(g^{e}-\frac{1}{12}\right)+\frac{1}{2} \delta^{2} U^{E}+\frac{1}{2}\left(\delta^{2}\left(g^{e}-\frac{1}{12}\right)+\delta^{3} U^{E}\right)
$$

for each $j$.

Now suppose that the prime minister is competent and belongs to party $L$. Then, if $\omega \geq \frac{1}{2}$ the policy is $p=1$ and there is an early election with probability $\frac{1}{2}$. If $\omega \leq \frac{1}{2}$, then $p=p^{*}$ and the prime minister can prove that she is competent. She will thus be nominated again and gain a large majority implying that

$$
U^{E L c}=\delta g^{e}+\frac{1}{2}\left(\delta^{3} g^{e}+\delta^{4} U^{E}\right)-\frac{1}{2} \delta \frac{1}{12}+\frac{1}{4} \delta^{2} U^{E}+\frac{1}{4}\left(\delta^{2} g^{e}+\delta^{3} U^{E}\right) .
$$

Along the same lines we derive that

$$
U^{E L c}=U^{E R c} .
$$


Equations (10)-(14) imply equation (9).

Lemma 6 Given the behavior of voters in early and regular elections and the nomination decision of parties, we can find off-the-equilibrium beliefs such that, in any period where a political decision is taken, the policy outcome is $p^{*}$ if the prime minister is competent and if there is no blockade, and $p=1$ otherwise.

Proof If the prime minister is in her second period, this follows because she seeks to maximize the voters' utility. Now suppose she is in her first period.

If she is competent and there is no blockade, proposing $p^{*}$ implies that she will be nominated again and reach the maximum time in office because her type will be revealed prior to the next regular election.

Now suppose she is incompetent or there is a blockade. Let the beliefs of voters be such that, if an early election takes place following a policy $p \neq 1$, this indicates that the prime minister is incompetent with probability 1 . Then the prime minister can not increase her reelection chances in an early election by deviating from the equilibrium policy $p=1$.

Alternatively, an incompetent or blocked prime minister may choose $p=1$ and not initiate early elections. The subsequent election is a regular election. If the off-the-equilibrium belief is such that the prime minister is competent with a probability less than $\frac{1}{2}$, then the prime minister's party prefers to nominate a newcomer

Finally, she may choose $p \neq 1$ and not initiate early elections. Again, if off-the-equilibrium beliefs ares such that the prime minister is competent with with a probability less than $\frac{1}{2}$, then she will not be nominated again.

Lemma 7 Consider a regular election in $T+2$ where the prime minister can be nominated for a second term. It is optimal to nominate the prime minister if and only if $p_{T}=p^{*}$.

Proof If $p_{T}=p^{*}$ then it has been revealed that the prime minister is competent. If she is nominated her party wins a large majority. In equilibrium, if $p_{T}=1$ and there has not been an early election in $T+1$, the probability that the prime minister is competent is weakly smaller than $\frac{1}{2}$ : if there had been no blockade the posterior probability of competence is 0 , otherwise it is equal to $\frac{1}{2}$. Consequently, if the prime minister competed against a newcomer, the latter would win with a large majority. The details of the argument are as in the proofs of Lemmas 3 and 4 .

Lemma 8 A prime minister who is competent and does not face a blockade does not initiate early elections. Consider a prime minister who is incompetent or blocked. If $k=\frac{5}{6}$, then off-the equilibrium beliefs can be chosen such that the prime minister does not opt for early elections. For $k=\frac{1}{6}$, the prime minister chooses early elections provided that $\delta$ does not exceed a critical value $\hat{\delta}$.

Proof If the prime minister is competent she can reach the maximum time in office if and only if she proposes $p^{*}$ and does not initiate early elections. In the following, consider a prime minister who is incompetent or blocked.

In the hypothesized equilibrium, incompetent and blocked prime ministers call for early elections 
whenever $k=\frac{1}{6}$. Bayes' rule implies that conditional on the events "early elections take place" and $k=\frac{1}{6}$ the probability that the prime minister is competent equals

$$
\begin{aligned}
\operatorname{Pr}\left\{t=c \mid E E, k=\frac{1}{4}\right\} & =\frac{\operatorname{Pr}\{t=c, \text { blockade }\}}{\operatorname{Pr}\{t=c, \text { blockade }\}+\operatorname{Pr}\{t=i\}} \\
& =\frac{\frac{1}{2} \times \frac{1}{2}}{\frac{1}{2} \times \frac{1}{2}+\frac{1}{2}}=\frac{1}{3}
\end{aligned}
$$

Consequently, if $k=\frac{1}{6}$, the voter in $T+1$ gets an expected payoff of $\pi_{E E}^{I}$ from electing the incumbent and an expected payoff of $\pi_{E E}^{N}$ from electing the newcomer, with

$$
\pi_{E E}^{I}=\frac{1}{3}\left(\delta g+\delta^{2} U^{E}\right)+\frac{2}{3}\left(\delta\left(g-\frac{1}{12}\right)+\delta^{2} U^{E}\right)
$$

and

$$
\pi_{E E}^{N}=\frac{1}{6}\left(\delta g+\delta^{3} g^{e}+\delta^{4} U^{E}\right)+\frac{5}{6}\left(\delta\left(g-\frac{1}{12}\right)+\delta^{2} U^{E}\right) .
$$

It is easy to show that $\pi_{E E}^{I}>\pi_{E E}^{N}$ if and only if

$$
g^{e}>\frac{2}{9} \frac{1}{\delta^{3}}+\frac{1}{1-\delta}\left(\frac{9}{8} \delta^{2}+\frac{5}{8} \delta^{3}-\frac{1}{2} \delta^{4}-\frac{1}{4} \delta^{5}-1\right) .
$$

For $\delta$ sufficiently small, the right hand side is negative. Hence, $\pi_{E E}^{I}>\pi_{E E}^{N}$ for all $g^{e}$ so that all voters have a strict preference for the prime minister. If off the equilibrium beliefs are such that the prime minister would not be nominated again in a regular election in $T+2$, then it is optimal to call early elections because the prime minister can stay in office for three instead of two periods.

Consider the case $k=\frac{5}{6}$ and suppose the prime minister would call early elections. Suppose voters have off-the-equilibrium beliefs such that the probability that the prime minister is competent is again equal to $\frac{1}{3}$. Then voters prefer the newcomer, since he is both younger (i.e., reelectable) and more likely to be competent than the incumbent. Hence, prime minister prefers to stay in office until the next regular election.

\section{A.3 Proof of Proposition 3}

Suppose off-equilibrium beliefs are such that whenever the incumbent calls for early elections, voters and party members believe her to be incompetent with probability 1 . These beliefs imply that the incumbent does never call for early elections. The remainder of the proof follows from proof of Proposition 1.

\section{A.4 Proof of Proposition 4}

Suppose first that a competent prime minister can choose a policy that reveals her competence to the voters prior to the next regular election. Then the prime minister will be nominated for a second time and get a large majority because in her last period she maximizes voter utility. If the equilibrium is such that a competent prime minister can always implement such a policy, this implies that she has no incentive to initiate early elections because she can be sure to reach the maximal time in office. But this implies that an early election could only be called for by an incompetent prime minister. But then an early election who would be lost and will not be 
initiated.

Now suppose that there are political blockades which imply that a competent prime minister can not reveal her type to the voters. Moreover suppose there is a separating equilibrium such that early elections are either triggered by an incompetent prime minister or by a competent but blocked prime minister. If only the incompetent one calls for early elections, voters will not elect her. Thus, it is not the incompetent type who calls for early elections. However, if only competent and blocked prime ministers call for early elections, they will be elected, and the incompetent type has an incentive to deviate and to call for early elections too. It follows that a fully separating equilibrium in pure strategies with early elections does not exist.

\section{B Proofs of the Propositions in Section 5}

\section{B.1 Proof of Proposition 5}

The proof proceeds in three steps. We first compute the utility of voters in the hypothesized equilibrium (Lemma 9). For the second step, we take it as given that political blockades occur and show that the prime minister's policy proposals, the party's nomination decisions and the behaviour of voters are mutually best responses (Lemmas 10 - 12). In the final step, we endogenize the political blockade (Lemmas 13 and 14).

Lemma 9 Suppose that Proposition 5 is true. The expected utility, $U^{N}(\theta)$, of voter type $\theta$ prior to an election where both parties are nominating a newcomer and prior to learning the next period's $g$ equals

$$
U^{N}(\theta)=\frac{\delta g^{e}\left(1+\frac{1}{2} \delta^{3}\right)-\frac{1}{2}\left(\delta+\delta^{3}\right) p^{c}(\theta)-\left(\frac{1}{2}-\frac{1}{16}\right) \delta p^{i}(\theta)}{1-\frac{1}{2} \delta^{4}-\frac{1}{2} \delta^{2}},
$$

where $p^{c}(\theta)=\left(\theta-\frac{1}{2}\right)^{2}$ is the expected per period utility loss given that $p=p^{*}\left(\frac{1}{2}\right)$ and $p^{i}(\theta)=p^{c}(\theta)+\frac{1}{12}$ is the expected per period utility loss given that $p=1$.

Proof We first compute the continuation utility $U^{N}(\theta)$ of a voter with type $\theta$ prior to an election campaign (i.e., before observing $\beta$ ) where both parties nominate a newcomer and prior to observing the next period's realization of $g$.

Suppose that both parties compete with a newcomer. We will verify below that $\beta=1(\beta=-1)$ implies that party $L(R)$ wins with a large majority and that $\beta=0$ implies that either party wins with probability $\frac{1}{2}$ and has only a small majority in case of winning. It is straightforward to verify that all of these events occur with equal probability. Hence,

$$
U^{N}(\theta)=\frac{1}{4}\left[L^{l}(\theta)+L^{s}(\theta)+R^{s}(\theta)+R^{l}(\theta)\right]
$$

where $L^{l}(\theta)$ is the continuation utility if party $L$ wins with a large majority and $L^{s}(\theta)$ is the continuation utility that applies if the majority is small. $R^{l}(\theta)$ and $R^{s}(\theta)$ are defined in the same way.

The payoff given that party $L$ wins with a large majority is based on expectations about the prime minister's type conditional on the event $\beta=1$,

$$
\begin{aligned}
L^{l}(\theta) & =\operatorname{pr}\left(t^{L}=c \mid \beta=1\right) L^{l c}(\theta)+\operatorname{pr}\left(t^{L}=i \mid \beta=1\right) L^{l i}(\theta) \\
& =\eta L^{l c}(\theta)+(1-\eta) L^{l i}(\theta)
\end{aligned}
$$


$L^{l c}(\theta)\left(L^{l i}(\theta)\right)$ is the expected continuation utility conditional on the events $\beta=1$ and $t^{L}=c$ $\left(t^{L}=i\right)$. In the hypothesized equilibrium, a competent prime minister stays in office for two periods because in case of having a large majority he can reveal his type during his first term with probability 1 . This implies

$$
L^{l c}(\theta)=\left(\delta+\delta^{3}\right)\left(g-p^{c}(\theta)\right)+\delta^{4} U(\theta)
$$

where $p^{c}(\theta):=\int_{0}^{1}\left(\theta+w-\left(\frac{1}{2}+w\right)\right)^{2} d w=\left(\theta-\frac{1}{2}\right)^{2}$. By contrast, an incompetent politician stays in office for only one period. Since his type becomes common knowledge the party nominates a newcomer in the next regular election. This implies

$$
L^{l i}(\theta)=\delta\left(g-p^{i}(\theta)\right)+\delta^{2} U(\theta)
$$

where $p^{i}(\theta):=\int_{0}^{1}(\theta+w-1)^{2} d w=\frac{1}{3}\left(\theta^{3}-(\theta-1)^{3}\right)$.

If party $L$ wins with a small majority, then, the continuation utility $L^{s}(\theta)$ is given by

$$
\begin{aligned}
L^{s}(\theta) & =\operatorname{pr}\left(t^{L}=c \mid \beta=0\right) L^{s c}(\theta)+\operatorname{pr}\left(t^{L}=i \mid \beta=0\right) L^{s i}(\theta) \\
& =\frac{1}{2} L^{s c}(\theta)+\frac{1}{2} L^{s i}(\theta)
\end{aligned}
$$

where $L^{s i}(\theta)=L^{l i}(\theta)$ because the behavior of an incompetent politician does not depend on the size of the majority. By contrast, a competent politician can choose $p=\frac{1}{2}+w$ if $w \leq \frac{1}{2}$ and has to choose $p=1$ otherwise. Hence,

$$
\begin{aligned}
L^{s c}(\theta) & =\operatorname{pr}\left(w \leq \frac{1}{2}\right) L_{n b}^{s c}(\theta)+\operatorname{pr}\left(w>\frac{1}{2}\right) L_{b}^{s c} \\
& =\frac{1}{2} L^{l c}(\theta)+\frac{1}{2} L_{b}^{s c}(\theta),
\end{aligned}
$$

$L_{b}^{s c}(\theta)$ is the continuation utility that applies if the president is blocked. In an equilibrium without early elections,

$$
L_{b}^{s c}(\theta)=\delta\left(g-p_{b}^{L c}(\theta)\right)+\delta^{2} U(\theta) .
$$

where $p_{b}^{L c}(\theta):=\int_{\frac{1}{2}}^{1}(\theta+w-1)^{2} d w=\frac{1}{3}\left(\theta^{3}-\left(\theta-\frac{1}{2}\right)^{3}\right)$ is the expected utility that is realized if the president is blocked.

Along the same lines one can derive the corresponding expressions for $R^{s}(\theta)$ and $R^{l}(\theta)$. Substituting the resulting formulas into (16) and using the assumption $\eta=\frac{3}{4}$ yields

$$
U^{N}(\theta)=\frac{\delta g^{e}\left(1+\frac{1}{2} \delta^{3}\right)-\frac{1}{2}\left(\delta+\delta^{3}\right) p^{c}(\theta)-\left(\frac{1}{2}-\frac{1}{16}\right) \delta p^{i}(\theta)}{1-\frac{1}{2} \delta^{4}-\frac{1}{2} \delta^{2}} .
$$

Taking the political blockades as given, it follows from Lemma 2 that the policy outcome in any period is $p^{*}\left(\frac{1}{2}\right)$ if the prime minister is competent and if there is no blockade, and $p=1$ otherwise.

Lemma 10 Consider a regular election where two newcomers are running. Party $L(R)$ wins with a large majority if and only if $\beta=1(\beta=-1)$. If $\beta=0$, then the winning party has a small majority, and each party wins with probability $\frac{1}{2}$. 


\section{Proof}

Case 1. Suppose the election campaign ends with a signal in favor of the left candidate $\beta=1$. We show in the following that, conditional on this event, for a majority of voters a large majority for party $L$ is the preferred outcome of the election. All graphs are drawn under the assumption that $g=\frac{1}{4}$.

Step 1. Consider first the comparison between a large majority for party $L$ and a large majority for party $R$. Given the posterior beliefs, the expected utility if $L$ wins a large majority is given by $L^{l}(\theta)$ whereas the expected utility if party $R$ wins a large majority is given by

$$
(1-\eta) R^{l c}+\eta R^{L i}
$$

where the symmetry of equilibria implies that $R^{l c}=L^{l c}$ and $L^{l i}=R^{l i}$. Hence, a voter of type $\theta$ prefers a large majority for $L$ over a large majority for $R$ if and only if $L^{l c}(\theta)-L^{l i}(\theta)>0$. The following graph shows that this statement is true for all $\theta$. Hence, all voters prefer a large majority for the more competent candidate over a large majority for the less competent candidate.

Figure 4: A large majority for $L$ vs a large majority for $R$ following $\beta=1$

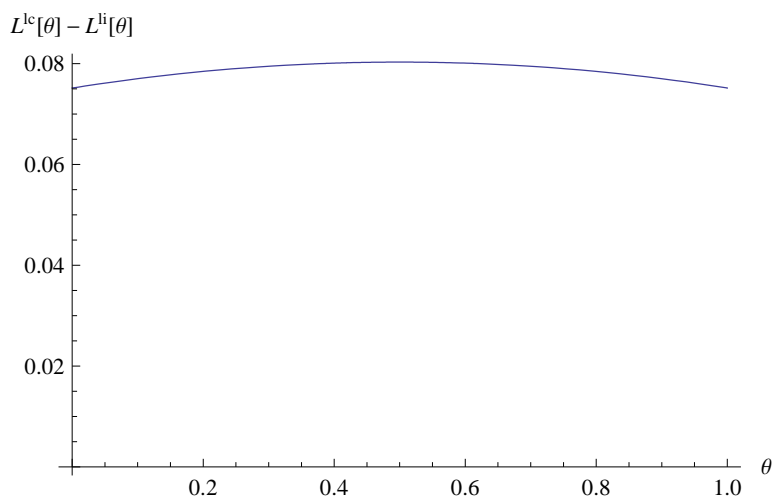

Step 2. We now investigate the set of voters who prefer a large majority for party $L$ over a small majority for party $L$. The expected utility if party $L$ wins a small majority is given by

$$
\eta L^{s c}+(1-\eta) L^{s i}
$$

where in an equilibrium without early elections $L^{s i}=L^{l i}$. Hence, a voter of type $\theta$ prefers a large majority for $L$ over a small majority for $L$ if and only if $L^{l c}(\theta)-L^{s c}(\theta)>0$. Figure 5 shows that this statement is true for all $\theta \geq 0.31$, that is only the voters whose ideal policy is very left benefit from a blockade.

Step 3. Using the same arguments as in Step 2, we find that all voters with types $\theta \leq 0.69$ prefer a large majority for party $R$ over a small majority for party $R$. By Step 1 all voters prefer a large majority for $L$ over a large majority for $R$. Hence, we can conclude that a all voters with types $\theta \leq 0.69$ prefer a large majority for party $L$ over a small majority for party $R$.

We conclude from Steps 1 - 3 that all voters with types between 0.31 and 0.69 prefer a large majority for party $L$ over any alternative outcome of the election. Assumption 3 implies that this is a majority of voters. Assumption 4 implies that these voters vote for party $L$. 
Case 2. A symmetric argument establishes that party $R$ will win with a large majority if the election campaign ends with a signal in favor of the right candidate $\beta=-1$.

Case 3. Suppose that $\beta=0$. Then, the posterior beliefs of the voters are such that both candidates are equally likely to be competent. Moreover, both parties behave identically in case of winning a large majority, implying that all voters are indifferent between a large majority for $L$ and large majority for $R$. Consequently, a voter of type $\theta$ prefers a small majority for party $L$ over a small majority for party $R$ if and only if $L^{s}(\theta) \geq R^{s}(\theta)$. A straightforward calculation shows that these are all voters with an ideal policy to the left of the median, i.e., all voters with $\theta \leq \frac{1}{2}$.

We now show that an incumbent who had the opportunity to prove that he is competent in the previous period will win with a large majority if he runs again.

Lemma 11 Suppose an incumbent has proven to be of type $c$. If nominated again, she will win with a large majority.

Proof Consider an election where an incumbent from party $R$ who has proven to be of type $c$ and runs again. If she is reelected with a large majority, a type $\theta$ voter realizes utility $O C^{l}(\theta):=\delta\left(g-p^{c}(\theta)\right)+\delta^{2} U(\theta)$.

If the candidate from the left party has a good signal, $\beta=1$, then the expected payoff from a large majority for party $L$ equals $Y G^{l}(\theta):=\eta L^{l c}(\theta)+(1-\eta) L^{l i}(\theta)$. Since $L^{l c}(\theta)>L^{l i}(\theta)$ this is an upper bound for the expected payoff that is realized if $L$ gains a large majority.

The following graph shows that $O C^{l}(\theta)>Y G^{l}(\theta)$ for all $\theta$. Hence, all voters prefer a large majority for the incumbent over a large majority for the newcomer, whatever the outcome of the election campaign. ${ }^{24}$

The set of voters who prefer a large majority for the incumbent over a small majority for the incumbent is given by the voters such that $\delta\left(g-p^{c}(\theta)\right)+\delta^{2} U^{N}(\theta)>\frac{1}{2}\left(\delta\left(g-p^{c}(\theta)\right)+\delta^{2} U^{N}(\theta)\right)+$ $\frac{1}{2}\left(\delta\left(g-p_{b}^{R c}(\theta)\right)+\delta^{2} U^{N}(\theta)\right)$. Straightforward computations show that these are the voters with $\theta<0.632$.

We can use the arguments from the proof of Proposition 10 to argue that all voters with $\theta>0.31$ prefer a large majority for the incumbent over a small majority for the left party. In summary, all voters with types between 0.31 and 0.632 prefer a large majority for the incumbent over any other outcome. By assumptions 3 and 4 this implies that the incumbent wins with a large majority.

Now suppose that the policy outcome has been $p=1$. From the perspective of voters this indicates that either there has been a blockade - conditional on this event the prime minister is competent with probability $\frac{1}{2}$ - or there has not been a blockade and prime minister is incompetent with probability 1 . The arguments in the proof of Lemma 4 imply that in this situation all voters with preferences in a neighborhood of the median would prefer a large majority for

\footnotetext{
${ }^{24}$ The inequality $O C^{l}(\theta)>Y G^{l}(\theta)$ can be manipulated analytically to obtain an upper bound on $\eta$. If $\eta$ was very close to 1 then the new candidate would be almost as likely by of type $c$ as the incumbent. Moreover, the new candidate has the advantage of being able to run in two consecutive elections. Hence, for $\eta$ very close to one $O C^{l}(\theta)>Y G^{l}(\theta)$ does not hold. By contrast, assuming that $\eta=\frac{3}{4}$ implies that a competent incumbent will always win against a newcomer.
} 
Figure 5: A large majority for a competent incumbent vs. a large majority for a new candidate with a good signal

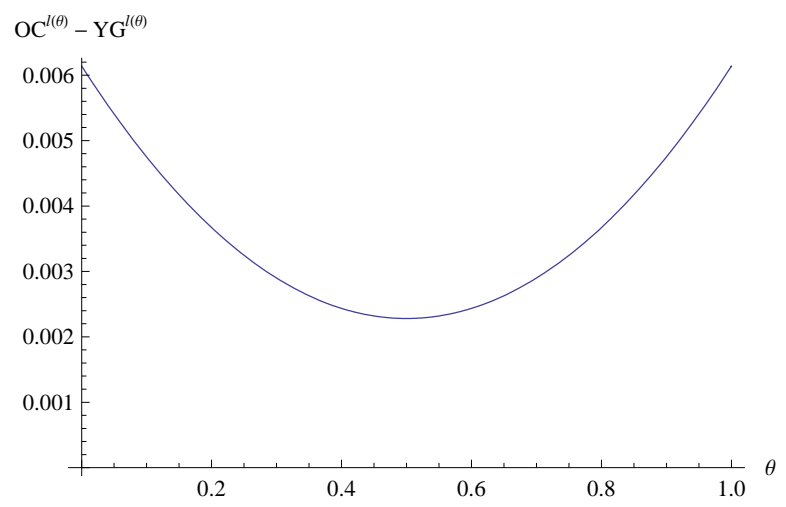

the newcomer over any other outcome if the prime minister was nominated again, which implies that the prime minister's party prefers to nominate a newcomer. This is summarized in the following Lemma, which we state without proof.

Lemma 12 Suppose an incumbent has implemented $p=1$. If nominated, the other candidate will win with a large majority.

We now turn to the incentives of parties to enact political blockades. Without loss of generality, we study only the incentives for the left party. We first derive the left party's payoffs in equilibrium. Prior to an election campaign with two newcomers, the left party's payoff $V_{L}$ is given by

$$
V_{L}=\frac{1}{4}\left(S_{L}^{L l}+S_{L}^{L s}+S_{L}^{R l}+S_{L}^{R s}\right),
$$

where $S_{L}^{L l}$ is the expected payoff of party $L$ conditional on winning a large majority in a regular election where two newcomers are running. $S_{L}^{L s}$ is the expected payoff in case of winning a small majority. $S_{L}^{R l}$ and $S_{L}^{R s}$ are the payoffs of the left party if the right party wins. We have that

$$
\begin{aligned}
S_{L}^{L l} & =\eta\left(1+\delta+\delta^{2}+\delta^{3}+\delta^{4} T_{L}\right)+(1-\eta)\left(1+\delta+\delta^{2} T_{L}\right) \\
S_{L}^{L s} & =\frac{1}{2}\left(1+\delta+\delta^{2}+\delta^{3}+\delta^{4} T_{L}\right)+\frac{1}{2}\left(1+\delta+\delta^{2} T_{L}\right) \\
S_{L}^{R l} & =\eta \delta^{4} T_{L}+(1-\eta) \delta^{2} T_{L} \\
S_{L}^{R l} & =\frac{1}{2} \delta^{4} T_{L}+\frac{1}{2} \delta^{2} T_{L} .
\end{aligned}
$$

Substituting these expressions into (24) yields

$$
V_{L}=\frac{1+\delta+\frac{1}{2}\left(\eta+\frac{1}{2}\right)\left(\delta^{2}+\delta^{3}\right)}{2-\left(\eta+\frac{1}{2}\right) \delta^{4}-\left(\frac{3}{2}-\eta\right) \delta^{2}}
$$

It is now straightforward to verify that

$$
V_{L}=\frac{1}{2} \frac{1}{1-\delta} .
$$

Intuitively, this is the present value of an infinite stream of expected per period payoffs of $\frac{1}{2}$, where $\frac{1}{2}$ the probability to be in office in any one period. 
Lemma 13 Suppose $L$ has a small majority. It is optimal for the party to block any policy $p \geq 1$ if it expects that otherwise leftist voters would abstain in the future whenever there is an election where both parties nominate a newcomer and $\beta=0$.

Proof Suppose there is an alternative equilibrium where leftist voters abstain whenever $\beta=0$ and, as a consequence, party $R$ gains a large majority whenever $\beta=0$. In all other cases voting behavior is unaffected. In this alternative equilibrium the left party's payoff $V_{L A}$ is given by

$$
V_{L A}=\frac{1}{4}\left(S_{L A}^{L l}+S_{L A}^{L s}+S_{L A}^{R l}+S_{L A}^{R s}\right)
$$

where

$$
\begin{aligned}
S_{L A}^{L l} & =\eta\left(1+\delta+\delta^{2}+\delta^{3}+\delta^{4} T_{L}\right)+(1-\eta)\left(1+\delta+\delta^{2} T_{L}\right) \\
S_{L A}^{L s} & =\frac{1}{2} \delta^{4} T_{L}+\frac{1}{2} \delta^{2} T_{L} \\
S_{L A}^{R l} & =\eta \delta^{4} T_{L}+(1-\eta) \delta^{2} T_{L} \\
S_{L A}^{R l} & =\frac{1}{2} \delta^{4} T_{L}+\frac{1}{2} \delta^{2} T_{L} .
\end{aligned}
$$

Substituting these expressions into (27) yields

$$
V_{L A}=\frac{\frac{1}{2}(1+\delta)+\frac{1}{2} \eta\left(\delta^{2}+\delta^{3}\right)}{2-\left(\eta+\frac{1}{2}\right) \delta^{4}-\left(\frac{3}{2}-\eta\right) \delta^{2}}
$$

Assuming that a deviation affects future play of leftist voters, the maximal utility that the left party can obtain by deviating from blocking any policy $p \geq 1$ is given by

$$
1+\delta+\delta^{2}+\delta^{3} V_{L A}
$$

This is based on the assumption that the party can win the next regular election by deviating. Thereafter, the party has to nominate a newcomer and from then one the new equilibrium payoff becomes relevant. By contrast, if the party honors its implicit contract with leftist voters, then the payoff is given by

$$
1+\delta V_{L}
$$

Straightforward calculations show that for $\eta=\frac{3}{4}$ and for $\delta=\frac{1}{2}$ we have that

$$
1+\delta V_{L}>1+\delta+\delta^{2}+\delta^{3} V_{A L}
$$

This implies that the left party has no incentive to deviate.

Using the same argument, one can show that it is not in the party's interest to deviate from moving as close as possible to the median voter's preferred policy. Suppose that the party and the president would consider a deviation such that in one period a policy that is optimal for voters with types to the left of the median is implemented. If this implies that in future elections all voters in a neighborhood of the median vote for party $R$ whenever the race is close, such a deviation is not attractive.

Lemma 14 Consider a deviation of party $L$ that yields a short run gain for leftist voters. If 
this implies that in the future voters in the middle vote for party $R$ whenever there is an election where both parties nominate a newcomer and $\beta=0$, then such a deviation is not attractive.

\section{B.2 Proof of Proposition 6}

The proof proceeds in three steps. We first consider the incentives for a prime minister to call for early elections. Lemma 15 shows that it may happen that after the early election, voters consider the opposition party's candidate to be more competent. Lemma 16 shows that the prime minister nevertheless wants to call an early election even if the opposition party has a chance to win. Second, we derive voter utility in the hypothesized equilibrium (Lemma 17). Finally, we indicate the steps that are required to complete the proof, i.e., to verify that the hypothesized behavior constitutes indeed a stationary perfect Bayesian equilibrium.

The following Lemma provides a characterization of the beliefs of voters after an early election as a function of the outcome of the election campaign, $\beta^{\prime}$, preceding the early election. For ease of notation we suppress that all probabilities are conditional on the events that early elections take place, that $k=k_{L}$ and that the preceding regular election had $\beta=0$. Conditional on these

events, the probability that the prime minister is competent equals $\frac{1}{3}$, as in the basic model in Section 3.

Lemma 15 Suppose the prime minister belongs to party $L$. If $\eta=\frac{3}{4}$, then

$$
\operatorname{pr}\left(t^{L}=c \mid \beta^{\prime}=0\right)>\operatorname{pr}\left(t^{R}=c \mid \beta^{\prime}=0\right)
$$

if $\beta=1$ or $\beta=0$, and

$$
\operatorname{pr}\left(t^{L}=c \mid \beta^{\prime}=0\right)<\operatorname{pr}\left(t^{R}=c \mid \beta^{\prime}=0\right)
$$

if $\beta=-1$.

\section{Proof}

Case 1. Suppose that $\beta=0$. By definition of a conditional probability

$$
\operatorname{pr}\left(t^{L}=c \mid \beta^{\prime}=0\right)=\frac{\frac{1}{3} \operatorname{pr}\left(\beta^{\prime}=0 \mid t^{L}=c\right)}{\operatorname{pr}\left(\beta^{\prime}=0\right)},
$$

where

$$
\operatorname{pr}\left(\beta^{\prime}=0\right)=\frac{1}{3} \operatorname{pr}\left(\beta^{\prime}=0 \mid t^{L}=c\right)+\frac{2}{3} \operatorname{pr}\left(\beta^{\prime}=0 \mid t^{L}=i\right)
$$

Moreover, the assumption that $\alpha_{L}$ and $\alpha_{R}$ are independent random variables implies that

$$
\operatorname{pr}\left(\beta^{\prime}=0 \mid t^{L}=c\right)=\eta[k \eta+(1-k)(1-\eta)]+(1-\eta)[k(1-\eta)+(1-k) \eta]
$$

and

$$
\operatorname{pr}\left(\beta^{\prime}=0 \mid t^{L}=i\right)=(1-\eta)[k \eta+(1-k)(1-\eta)]+\eta[k(1-\eta)+(1-k) \eta]
$$

Combining equations (29) - (32) yields

$$
\operatorname{pr}\left(t^{L}=c \mid \beta^{\prime}=0\right)=\frac{\frac{1}{3}\left\{2 \eta(1-\eta)+k(2 \eta-1)^{2}\right\}}{-\frac{1}{3} k(2 \eta-1)^{2}+\frac{2}{3}\left\{(1-\eta)^{2}+\eta(1-\eta)+\eta^{2}\right\}} .
$$


Also,

$$
\operatorname{pr}\left(t^{R}=c \mid \beta^{\prime}=0\right)=\frac{k_{L} \operatorname{pr}\left(\beta^{\prime}=0 \mid t^{R}=c\right)}{\operatorname{pr}\left(\beta^{\prime}=0\right)},
$$

where

$$
\begin{aligned}
\operatorname{pr}\left(\beta^{\prime}=0 \mid t^{R}=c\right)= & \frac{1}{3} \operatorname{pr}\left(\beta^{\prime}=0 \mid t^{R}=c, t^{L}=c\right) \\
& +\frac{2}{3} \operatorname{pr}\left(\beta^{\prime}=0 \mid t^{R}=c, t^{L}=i\right) \\
= & \frac{1}{3}\left\{\eta^{2}+(1-\eta)^{2}\right\}+\frac{2}{3}\{2 \eta(1-\eta)\}
\end{aligned}
$$

Combining equations (30)-(32) to solve for $\operatorname{pr}\left(\beta^{\prime}=0\right)$ and equations (34) and (35) yields

$$
\operatorname{pr}\left(t^{R}=c \mid \beta^{\prime}=0\right)=\frac{k\left[\frac{1}{3}\left\{\eta^{2}+(1-\eta)^{2}\right\}+\frac{2}{3}\{2 \eta(1-\eta)\}\right]}{-\frac{1}{3} k(2 \eta-1)^{2}+\frac{2}{3}\left\{(1-\eta)^{2}+\eta(1-\eta)+\eta^{2}\right\}}
$$

It follows from equations (36) and (33) that

$$
\operatorname{pr}\left(t^{L}=c \mid \beta^{\prime}=0\right)>\operatorname{pr}\left(t^{N}=c \mid \beta^{\prime}=0\right) \quad \Longleftrightarrow \quad k_{L}<\frac{1}{3} .
$$

With $k_{L}=\frac{1}{6}$, it follows that $\operatorname{pr}\left(t^{L}=c \mid \beta^{\prime}=0\right)>\operatorname{pr}\left(t^{N}=c \mid \beta^{\prime}=0\right)$.

Case 2. Suppose that $\beta^{\prime}=1$. Using the same arguments as in Case 1, we derive

$$
\operatorname{pr}\left(t^{L}=c \mid \beta^{\prime}=1\right)=\frac{\eta}{2-\eta} .
$$

and

$$
\operatorname{pr}\left(t^{N}=c \mid \beta^{\prime}=1\right)=\frac{k\left[\frac{1}{3} \eta(1-\eta)+\frac{2}{3}(1-\eta)^{2}\right]}{\frac{1}{3}(2-\eta)\{k(1-\eta)+(1-k) \eta\}}
$$

It follows that,

$$
\operatorname{pr}\left(t^{L}=c \mid \beta^{\prime}=1\right)>\operatorname{pr}\left(t^{N}=c \mid \beta^{\prime}=1\right) \quad \Longleftrightarrow \quad k<\frac{\eta^{2}}{2+3 \eta^{2}-4 \eta} .
$$

With $\eta=\frac{3}{4}, \frac{\eta^{2}}{2+3 \eta^{2}-4 \eta}>\frac{1}{6}$. It follows that $\operatorname{pr}\left(t^{L}=c \mid \beta^{\prime}=1\right)>\operatorname{pr}\left(t^{N}=c \mid \beta^{\prime}=1\right)$.

Case 3. Suppose that $\beta^{\prime}-=1$. Using the same arguments as Case 1, we derive

$$
\operatorname{pr}\left(t^{L}=c \mid \beta^{\prime}=-1\right)=\frac{1-\eta}{1+\eta} .
$$

and

$$
\operatorname{pr}\left(t^{N}=c \mid \beta^{\prime}=-1\right)=\frac{k\left[\frac{1}{3} \eta(1-\eta)+\frac{2}{3} \eta^{2}\right]}{\frac{1}{3}(1+\eta)\{k \eta+(1-k)(1-\eta) \eta\}}
$$

It follows that,

$$
\begin{aligned}
& \operatorname{pr}\left(t^{L}=c \mid \beta^{E E}=-1, E E, k\right)>\operatorname{pr}\left(t^{N}=c \mid \beta^{E E}=-1, E E, k\right) \\
& \Longleftrightarrow k<\frac{(1-\eta)^{2}}{(1-\eta)^{2}+2 \eta^{2}}
\end{aligned}
$$


With $\eta=\frac{3}{4}, \frac{(1-\eta)^{2}}{(1-\eta)^{2}+2 \eta^{2}}<\frac{1}{6}$. Hence, $\operatorname{pr}\left(t^{L}=c \mid \beta^{\prime}=-1\right)<\operatorname{pr}\left(t^{N}=c \mid \beta^{\prime}=-1\right)$.

Lemma 16 Suppose the prime minister belongs to party $L$. Suppose there is a blockade or that the prime minister is incompetent. Suppose that $k=k_{L}$ and that the preceding regular election in period $T$ had $\beta=0$. Suppose that the prime minister would not be nominated again if there was a regular election in $T+2$. Suppose that the prime minister will win an early election if and only if $\beta \neq-1$. Then it is optimal for the prime minister to call for an early election.

Proof If the prime minister does not initiate early elections, her payoff as of period $T+1$ equals 1 because she can stay in office until $T+2$. If she wins an early election her expected payoff equals $(1+\delta) \operatorname{pr}\left(\beta^{\prime} \neq-1 \mid t^{L}\right)$ because in case of winning she stays in office until $T+3$ and loses her office otherwise. Suppose first that $t^{L}=i$. Then,

$$
\begin{aligned}
\operatorname{pr}\left(\beta^{\prime}=-1 \mid t^{L}=i\right)= & k_{L} \operatorname{pr}\left(\beta^{\prime}=-1 \mid t^{R}=c, t^{L}=i\right) \\
& +\left(1-k_{L}\right) \operatorname{pr}\left(\beta^{\prime}=-1 \mid t^{R}=i, t^{L}=i\right) \\
= & k_{L} \eta^{2}+\left(1-k_{L}\right) \eta(1-\eta)
\end{aligned}
$$

Hence, an incompetent prime minister calls for early elections if

$$
(1+\delta)\left(1-k_{L} \eta^{2}-\left(1-k_{L}\right) \eta(1-\eta)\right)>1
$$

With $\delta=\eta=\frac{3}{4}$ and $k_{L}=\frac{1}{6}$, this condition is fulfilled.

Now suppose that the prime minister is competent, then

$$
\operatorname{pr}\left(\beta^{\prime}=-1 \mid t^{L}=c\right)=k_{L} \eta(1-\eta)+\left(1-k_{L}\right)(1-\eta)^{2}
$$

which is strictly smaller than $\operatorname{pr}\left(\beta^{\prime}=-1 \mid t^{L}=i\right)$. Hence a competent prime minister also opts for early elections.

Lemma 17 The expected utility, $U^{E}(\theta)$, of voter type $\theta$ prior to an election where both parties are nominating a newcomer and prior to learning the next period's $g$ equals

$$
U^{E}(\theta)=\frac{q g^{e}-r p^{c}(\theta)-s p^{i}(\theta)}{1-u},
$$

where

$$
\begin{aligned}
q:= & \delta+\frac{3}{8} \lambda \delta^{2}+\left(\frac{1}{8}+\frac{1}{2} \eta+\frac{1}{4} \lambda \delta\left(\frac{1}{2} \sigma^{c}+\sigma^{i}\right)\right) \delta^{3} \\
r:= & \delta\left(\frac{5}{16}+\frac{1}{2}(1-\eta)+\frac{1}{4} \lambda \delta\left(\frac{1}{2} \gamma^{c}+\gamma^{i}\right)\right) \\
s:= & \frac{1}{8} \lambda \alpha^{c} \delta^{2}+\left(\frac{1}{8}+\frac{1}{2} \eta+\frac{1}{4} \lambda \delta\left(\frac{1}{2} \sigma^{c}+\sigma^{i}\right)\right)\left(\delta+\delta^{3}\right), \\
u:= & \left(\frac{3}{8}(1-\lambda)+\frac{1}{2}(1-\eta)\right) \delta^{2}+\lambda\left(\frac{1}{8}\left(\alpha^{c}+\gamma^{c}\right)+\frac{1}{4}\left(\alpha^{i}+\gamma^{i}\right)\right) \delta^{3} \\
& +\left(\frac{1}{8}+\frac{1}{2} \eta\right) \delta^{4}+\lambda\left(\frac{1}{8} \sigma^{c}+\frac{1}{4} \sigma^{i}\right) \delta^{5} .
\end{aligned}
$$

and

$$
\alpha^{c}:=\operatorname{pr}\left(\beta^{\prime}=-1 \mid t^{L}=c\right)=1-k_{L} \eta(1-\eta)-\left(1-k_{L}\right)(1-\eta)^{2},
$$


is the probability that a competent incumbent wins an early election and

$$
\alpha^{i}:=\operatorname{pr}\left(\beta^{\prime}=-1 \mid t^{L}=i\right)=1-k_{L} \eta^{2}-\left(1-k_{L}\right) \eta(1-\eta)
$$

is the probability that an competent incumbent wins.

$$
\sigma^{c}:=\operatorname{pr}\left(\beta^{\prime}=-1, t^{R}=c \mid t^{L}=c\right)=k_{L} \operatorname{pr}\left(\beta^{\prime}=-1, \mid t^{R}=c, t^{L}=c\right)=k_{L} \eta(1-\eta),
$$

is the joint probability that the incumbent loses and that the newcomer is competent given that the incumbent is competent, and

$$
\sigma^{i}:=k_{L} \eta^{2}
$$

is the joint probability that the incumbent loses and that the newcomer is competent given that the incumbent is not competent. Analogously, the joint probability that the incumbent loses and that the newcomer is incompetent is given by

$$
\gamma^{c}:=(1-\eta)^{2}\left(1-k_{L}\right)
$$

if the incumbent is competent and by

$$
\gamma^{i}:=\eta(1-\eta)\left(1-k_{L}\right)
$$

if the incumbent is incompetent. Finally $\lambda=\frac{1}{2}$ is the probability that $k=k_{L}=\frac{1}{6}$.

Proof An election where both nominate a newcomer leads to a large majority for party $L(R)$ if $\beta=1(\beta=-1)$ which happens with probability $\frac{1}{4}$. Conditional on $\beta=0$ either party has an equal chance of winning with a small majority. Hence,

$$
U^{E}(\theta)=\frac{1}{4}\left[\bar{L}^{l}(\theta)+\bar{L}^{s}(\theta)+\bar{R}^{s}(\theta)+\bar{R}^{l}(\theta)\right]
$$

where $\bar{L}^{l}(\theta)$ is the continuation utility if party $L$ wins with a large majority and $\bar{L}^{s}(\theta)$ is the continuation utility that applies if the majority is small, etc.

In case of winning with a large majority, there is no political blockade. Hence,

$$
\bar{L}^{l}(\theta)=\eta \bar{L}^{l c}(\theta)+(1-\eta) \bar{L}^{l i}(\theta),
$$

where

$$
\bar{L}^{l c}(\theta)=\left(\delta+\delta^{3}\right)\left(g-p^{c}(\theta)\right)+\delta^{4} U^{E}(\theta)
$$

and

$$
\bar{L}^{l i}(\theta)=\delta\left(g-p^{i}(\theta)\right)+\delta^{2} U^{E}(\theta)
$$

Again by symmetry $\bar{L}^{l}(\theta)=\bar{R}^{l}(\theta)$.

If party $L$ wins with a small majority, then, the continuation utility $\bar{L}^{s}(\theta)$ is given by

$$
\bar{L}^{s}(\theta)=\frac{1}{2} \bar{L}^{s c}(\theta)+\frac{1}{2} \bar{L}^{s i}(\theta)
$$

where

$$
\bar{L}^{s c}(\theta)=\frac{1}{2} \bar{L}_{n b}^{s c}(\theta)+\frac{1}{2} \bar{L}_{b}^{s c}(\theta)
$$


where $\bar{L}_{n b}^{s c}$ is the continuation utility that applies if $\omega \leq \frac{1}{2}$ and there is no blockade, and $\bar{L}_{b}^{s c}$ is the continuation utility that applies otherwise. If there is no blockade, a competent prime minister can prove his competence which implies that

$$
\bar{L}_{n b}^{s c}(\theta)=\bar{L}^{l c}(\theta)
$$

Let $\lambda$ be the probability that the opposition competence equals $k$ so that the incumbent initiates early elections. With probability $1-\lambda$ there is no early election but a regular election where both parties nominate a newcomer. Hence,

$$
\bar{L}_{b}^{s c}(\theta)=\delta\left(g^{e}-p_{b}^{L c}(\theta)\right)+(1-\lambda) U^{E}(\theta)+\lambda X^{c},
$$

where

$$
X^{c}:=\alpha^{c}\left[\delta^{2}\left(g^{e}-p^{c}(\theta)\right)+\delta^{3} U^{E}(\theta)\right]+\sigma^{c} \delta \bar{R}^{l c}(\theta)+\gamma^{c} \delta \bar{R}^{l i}(\theta)
$$

Analogously, we derive

$$
\bar{L}^{s i}(\theta)=\delta\left(g^{e}-p^{i}(\theta)\right)+(1-\lambda) U^{E}(\theta)+\lambda X^{i}
$$

where

$$
X^{i}:=\alpha^{i}\left[\delta^{2}\left(g^{e}-p^{i}(\theta)\right)+\delta^{3} U^{E}(\theta)\right]+\sigma^{i} \delta \bar{R}^{l c}(\theta)+\gamma^{i} \delta \bar{R}^{l i}(\theta)
$$

The expressions for party $R$ are derived in the same way. Substituting all of the resulting expressions into (42) und using that $p_{b}^{L c}(\theta)+p_{b}^{R c}(\theta)=p^{i}(\theta)$ establishes the Lemma.

The remaining steps to complete the proof of Proposition 6 are similar to those for the proof of Proposition 5. We therefore only sketch the arguments. ${ }^{25}$ We first verify that Lemma 10 also holds in the current setting. The arguments and the results are exactly the same as in the proof of Lemma 10. We further verify that an early election is indeed such that the incumbent wins with a large majority if $\beta \neq-1$ and that the opposition party wins with a large majority otherwise. Therefore it is necessary to use the appropriate posterior beliefs on candidate competence when computing expected utility conditional on the outcome of the early election campaign and to adjust for the fact that the incumbent has a shorter time horizon than the newcomer. Given these modifications, the arguments and the results which characterize the outcome of early elections are same as in the proof of Lemma 10. Finally, we show that also Lemmas 11-14 go through.

\footnotetext{
${ }^{25}$ Details are available from the authors upon request.
} 


\section{SFB 649 Discussion Paper Series 2008}

For a complete list of Discussion Papers published by the SFB 649, please visit http://sfb649.wiwi.hu-berlin.de.

001 "Testing Monotonicity of Pricing Kernels" by Yuri Golubev, Wolfgang Härdle and Roman Timonfeev, January 2008.

002 "Adaptive pointwise estimation in time-inhomogeneous time-series models" by Pavel Cizek, Wolfgang Härdle and Vladimir Spokoiny, January 2008.

003 "The Bayesian Additive Classification Tree Applied to Credit Risk Modelling" by Junni L. Zhang and Wolfgang Härdle, January 2008.

004 "Independent Component Analysis Via Copula Techniques" by Ray-Bing Chen, Meihui Guo, Wolfgang Härdle and Shih-Feng Huang, January 2008.

005 "The Default Risk of Firms Examined with Smooth Support Vector Machines" by Wolfgang Härdle, Yuh-Jye Lee, Dorothea Schäfer and Yi-Ren Yeh, January 2008.

006 "Value-at-Risk and Expected Shortfall when there is long range dependence" by Wolfgang Härdle and Julius Mungo, Januray 2008.

007 "A Consistent Nonparametric Test for Causality in Quantile" by Kiho Jeong and Wolfgang Härdle, January 2008.

008 "Do Legal Standards Affect Ethical Concerns of Consumers?" by Dirk Engelmann and Dorothea Kübler, January 2008.

009 "Recursive Portfolio Selection with Decision Trees" by Anton Andriyashin, Wolfgang Härdle and Roman Timofeev, January 2008.

010 "Do Public Banks have a Competitive Advantage?" by Astrid Matthey, January 2008.

011 "Don't aim too high: the potential costs of high aspirations" by Astrid Matthey and Nadja Dwenger, January 2008.

012 "Visualizing exploratory factor analysis models" by Sigbert Klinke and Cornelia Wagner, January 2008.

013 "House Prices and Replacement Cost: A Micro-Level Analysis" by Rainer Schulz and Axel Werwatz, January 2008.

014 "Support Vector Regression Based GARCH Model with Application to Forecasting Volatility of Financial Returns" by Shiyi Chen, Kiho Jeong and Wolfgang Härdle, January 2008.

015 "Structural Constant Conditional Correlation" by Enzo Weber, January 2008.

016 "Estimating Investment Equations in Imperfect Capital Markets" by Silke Hüttel, Oliver Mußhoff, Martin Odening and Nataliya Zinych, January 2008.

017 "Adaptive Forecasting of the EURIBOR Swap Term Structure" by Oliver Blaskowitz and Helmut Herwatz, January 2008.

018 "Solving, Estimating and Selecting Nonlinear Dynamic Models without the Curse of Dimensionality" by Viktor Winschel and Markus Krätzig, February 2008.

019 "The Accuracy of Long-term Real Estate Valuations" by Rainer Schulz, Markus Staiber, Martin Wersing and Axel Werwatz, February 2008.

020 "The Impact of International Outsourcing on Labour Market Dynamics in Germany" by Ronald Bachmann and Sebastian Braun, February 2008.

021 "Preferences for Collective versus Individualised Wage Setting" by Tito Boeri and Michael C. Burda, February 2008.

\section{SFB 649, Spandauer Straße 1, D-10178 Berlin http:/ / sfb649.wiwi.hu-berlin.de}

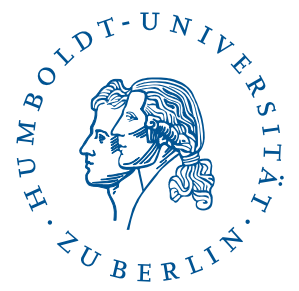


022 "Lumpy Labor Adjustment as a Propagation Mechanism of Business Cycles" by Fang Yao, February 2008.

023 "Family Management, Family Ownership and Downsizing: Evidence from S\&P 500 Firms" by Jörn Hendrich Block, February 2008.

024 "Skill Specific Unemployment with Imperfect Substitution of Skills" by Runli Xie, March 2008.

025 "Price Adjustment to News with Uncertain Precision" by Nikolaus Hautsch, Dieter Hess and Christoph Müller, March 2008.

026 "Information and Beliefs in a Repeated Normal-form Game" by Dietmar Fehr, Dorothea Kübler and David Danz, March 2008.

027 "The Stochastic Fluctuation of the Quantile Regression Curve" by Wolfgang Härdle and Song Song, March 2008.

028 "Are stewardship and valuation usefulness compatible or alternative objectives of financial accounting?" by Joachim Gassen, March 2008.

029 "Genetic Codes of Mergers, Post Merger Technology Evolution and Why Mergers Fail" by Alexander Cuntz, April 2008.

030 "Using R, LaTeX and Wiki for an Arabic e-learning platform" by Taleb Ahmad, Wolfgang Härdle, Sigbert Klinke and Shafeeqah Al Awadhi, April 2008.

031 "Beyond the business cycle - factors driving aggregate mortality rates" by Katja Hanewald, April 2008.

032 "Against All Odds? National Sentiment and Wagering on European Football" by Sebastian Braun and Michael Kvasnicka, April 2008.

033 "Are CEOs in Family Firms Paid Like Bureaucrats? Evidence from Bayesian and Frequentist Analyses" by Jörn Hendrich Block, April 2008.

034 "JBendge: An Object-Oriented System for Solving, Estimating and Selecting Nonlinear Dynamic Models" by Viktor Winschel and Markus Krätzig, April 2008.

035 "Stock Picking via Nonsymmetrically Pruned Binary Decision Trees" by Anton Andriyashin, May 2008.

036 "Expected Inflation, Expected Stock Returns, and Money Illusion: What can we learn from Survey Expectations?" by Maik Schmeling and Andreas Schrimpf, May 2008.

037 "The Impact of Individual Investment Behavior for Retirement Welfare: Evidence from the United States and Germany" by Thomas Post, Helmut Gründl, Joan T. Schmit and Anja Zimmer, May 2008.

038 "Dynamic Semiparametric Factor Models in Risk Neutral Density Estimation" by Enzo Giacomini, Wolfgang Härdle and Volker Krätschmer, May 2008.

039 "Can Education Save Europe From High Unemployment?" by Nicole Walter and Runli Xie, June 2008.

040 "Solow Residuals without Capital Stocks" by Michael C. Burda and Battista Severgnini, August 2008.

041 "Unionization, Stochastic Dominance, and Compression of the Wage Distribution: Evidence from Germany" by Michael C. Burda, Bernd Fitzenberger, Alexander Lembcke and Thorsten Vogel, March 2008

042 "Gruppenvergleiche bei hypothetischen Konstrukten - Die Prüfung der Übereinstimmung von Messmodellen mit der Strukturgleichungsmethodik" by Dirk Temme and Lutz Hildebrandt, June 2008.

043 "Modeling Dependencies in Finance using Copulae" by Wolfgang Härdle, Ostap Okhrin and Yarema Okhrin, June 2008.

044 "Numerics of Implied Binomial Trees" by Wolfgang Härdle and Alena Mysickova, June 2008.

\section{SFB 649, Spandauer Straße 1, D-10178 Berlin http:/ / sfb649.wiwi.hu-berlin.de}

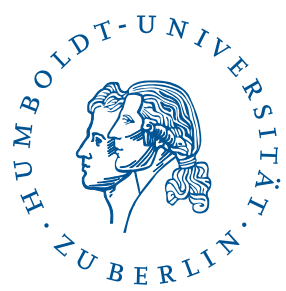


045 "Measuring and Modeling Risk Using High-Frequency Data" by Wolfgang Härdle, Nikolaus Hautsch and Uta Pigorsch, June 2008.

046 "Links between sustainability-related innovation and sustainability management" by Marcus Wagner, June 2008.

047 "Modelling High-Frequency Volatility and Liquidity Using Multiplicative Error Models" by Nikolaus Hautsch and Vahidin Jeleskovic, July 2008.

048 "Macro Wine in Financial Skins: The Oil-FX Interdependence" by Enzo Weber, July 2008.

049 "Simultaneous Stochastic Volatility Transmission Across American Equity Markets" by Enzo Weber, July 2008.

050 "A semiparametric factor model for electricity forward curve dynamics" by Szymon Borak and Rafał Weron, July 2008.

051 "Recurrent Support Vector Regreson for a Nonlinear ARMA Model with Applications to Forecasting Financial Returns" by Shiyi Chen, Kiho Jeong and Wolfgang K. Härdle, July 2008.

052 "Bayesian Demographic Modeling and Forecasting: An Application to U.S. Mortality" by Wolfgang Reichmuth and Samad Sarferaz, July 2008.

053 "Yield Curve Factors, Term Structure Volatility, and Bond Risk Premia" by Nikolaus Hautsch and Yangguoyi Ou, July 2008.

054 "The Natural Rate Hypothesis and Real Determinacy" by Alexander MeyerGohde, July 2008.

055 "Technology sourcing by large incumbents through acquisition of small firms" by Marcus Wagner, July 2008.

056 "Lumpy Labor Adjustment as a Propagation Mechanism of Business Cycle" by Fang Yao, August 2008.

057 "Measuring changes in preferences and perception due to the entry of a new brand with choice data" by Lutz Hildebrandt and Lea Kalweit, August 2008.

058 "Statistics E-learning Platforms: Evaluation Case Studies" by Taleb Ahmad and Wolfgang Härdle, August 2008.

059 "The Influence of the Business Cycle on Mortality" by Wolfgang $\mathrm{H}$. Reichmuth and Samad Sarferaz, September 2008.

060 "Matching Theory and Data: Bayesian Vector Autoregression and Dynamic Stochastic General Equilibrium Models" by Alexander Kriwoluzky, September 2008.

061 "Eine Analyse der Dimensionen des Fortune-Reputationsindex" by Lutz Hildebrandt, Henning Kreis and Joachim Schwalbach, September 2008.

062 "Nonlinear Modeling of Target Leverage with Latent Determinant Variables - New Evidence on the Trade-off Theory" by Ralf Sabiwalsky, September 2008.

063 "Discrete-Time Stochastic Volatility Models and MCMC-Based Statistical Inference" by Nikolaus Hautsch and Yangguoyi Ou, September 2008.

064 "A note on the model selection risk for ANOVA based adaptive forecasting of the EURIBOR swap term structure" by Oliver Blaskowitz and Helmut Herwartz, October 2008.

065 "When, How Fast and by How Much do Trade Costs change in the EURO Area?" by Helmut Herwartz and Henning Weber, October 2008.

066 "The U.S. Business Cycle, 1867-1995: Dynamic Factor Analysis vs. Reconstructed National Accounts" by Albrecht Ritschl, Samad Sarferaz and Martin Uebele, November 2008.

067 "Testing Multiplicative Error Models Using Conditional Moment Tests" by Nikolaus Hautsch, November 2008.

068 "Understanding West German Economic Growth in the 1950s" by Barry Eichengreen and Albrecht Ritschl, December 2008.

\section{SFB 649, Spandauer Straße 1, D-10178 Berlin} http:/ / sfb649.wiwi.hu-berlin.de

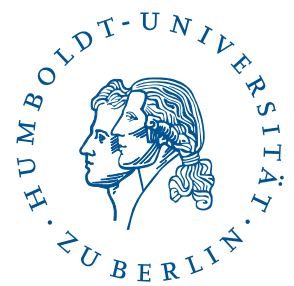


069 "Structural Dynamic Conditional Correlation" by Enzo Weber, December 2008.

070 "A Brand Specific Investigation of International Cost Shock Threats on Price and Margin with a Manufacturer-Wholesaler-Retailer Model" by Till Dannewald and Lutz Hildebrandt, December 2008.

071 "Winners and Losers of Early Elections: On the Welfare Implications of Political Blockades and Early Elections" by Felix Bierbrauer and Lydia Mechtenberg, December 2008. 